\title{
Smartphones in mental health: a critical review of background issues, current status and future concerns
}

\author{
Michael Bauer ${ }^{{ }^{*}}\left(\mathbb{D}\right.$, Tasha Glenn², John Geddes ${ }^{3}$, Michael Gitlin ${ }^{4}$, Paul Grof ${ }^{5,6}$, Lars V. Kessing ${ }^{7}$, Scott Monteith ${ }^{8}$, \\ Maria Faurholt-Jepsen ${ }^{7}$, Emanuel Severus ${ }^{1}$ and Peter C. Whybrow ${ }^{4}$
}

\begin{abstract}
There has been increasing interest in the use of smartphone applications (apps) and other consumer technology in mental health care for a number of years. However, the vision of data from apps seamlessly returned to, and integrated in, the electronic medical record (EMR) to assist both psychiatrists and patients has not been widely achieved, due in part to complex issues involved in the use of smartphone and other consumer technology in psychiatry. These issues include consumer technology usage, clinical utility, commercialization, and evolving consumer technology. Technological, legal and commercial issues, as well as medical issues, will determine the role of consumer technology in psychiatry. Recommendations for a more productive direction for the use of consumer technology in psychiatry are provided.
\end{abstract}

Keywords: Smartphone, Cellphone, Technology, Mental illness, Psychiatry, Wearables

\section{Background}

A smartphone is a transformational technology. The many benefits include instant communications and access to information from anywhere while using a simple, graphical, finger-based interface. One smartphone eliminates the need to carry many devices including a phone, camera, speakers, WiFi adapter, and a GPS system. A smartphone allows the user to download and run applications (apps). The built-in sensors can provide measurements and contextual information, and by integrating communications into an app, the user needs few connectivity skills. In 2012, a consumer smartphone had more than 100 times the computing power of the average satellite (NASA 2012).

Many thought the use of a smartphone in psychiatry would enable new measures of patient mental state and

\footnotetext{
*Correspondence: michael.bauer@uniklinikum-dresden.de

1 Department of Psychiatry and Psychotherapy, University Hospital Carl Gustav Carus, Medical Faculty, Technische Universität Dresden, Fetscherstr. 74, 01307 Dresden, Germany

Full list of author information is available at the end of the article
}

behavior to assist with patient screening, diagnosis, monitoring and treatment (Glenn and Monteith 2014a; Mohr et al. 2017; Luxton et al. 2011), such as for bipolar disorder (Faurholt-Jepsen et al. 2014, 2018; Harrison et al. 2016). The future is often envisioned in which actionable data from apps, both recommended by psychiatrists and selected by patients, are seamlessly returned to the EMR, and data from the apps would provide clinically useful measures to the physician and immediate feedback to assist patients. Although there are many mental health apps available for smartphones, their expected value has not been realized. This paper will discuss some of the complex reasons why the smartphone has not reached this potential for collecting patient data in psychiatry. Consumer technology usage, clinical utility, commercialization, and evolving consumer technology will be discussed, followed by recommendations to enhance the use of consumer technology in psychiatry. 


\section{Consumer technology usage}

\section{Smartphone use is not universal}

Smartphone use varies throughout the world. From a global perspective, in 2017 there were 5 billion unique mobile subscribers with $57 \%$ of connections using a smartphone (GSMA 2018a). For the 5 billion mobile subscribers, the top 3 uses of a cellphone are to make or receive cellular calls, send or receive text messages (SMS), and use messaging apps, while downloading and using apps for purposes other than messaging is ranked number 9 (GSMA 2018b). In 2018, 95\% of the US population owned a cellphone, and $77 \%$ of the cellphones were smartphones (Pew Research 2018). The percentage of cellphones that are smartphones in the US has remained constant since 2016 (Pew Research 2018).

Worldwide, smartphone use is unevenly distributed across the population. Older people use a smartphone significantly less often than younger people (Berenguer et al. 2017). In the US, about $40 \%$ of community dwelling adults age 65 years or older own a smartphone (Anderson and Perrin 2017) with barriers to use including visual and physical impairments (Kuerbis et al. 2017; Bauer et al. 2018a). Additionally, older people often use a smartphone as a standard feature phone, making calls but never downloading apps (Berenguer et al. 2017). People with low income may only have intermittent access to smartphones (Gonzales 2016). Smartphone use by those with serious mental illness is generally lower than for the general population (Klee et al. 2016; Glick et al. 2016; Abu Rahal et al. 2018; Carpenter-Song et al. 2018). Smartphone use is also associated with more education (Pew Research 2018).

\section{Alternatives to smartphones}

Consumers own many technologies in addition to a smartphone. In the US, in $2018,73 \%$ of the population owned a desktop or laptop, and 53\% owned a tablet (Pew Research 2018). Most owners of desktops or laptop also own peripheral devices such as printers and scanners. People use smartphones and desktops/laptops for different daily activities, varying by age (Bröhl et al. 2018). Although younger generations use a smartphone most frequently to perform daily activities, all age groups in an international sample preferred to use a desktop PC/ laptop for writing emails or letters, and for passing on confidential information (Bröhl et al. 2018). In an international sample of patients with bipolar disorder, $81 \%$ looked for information on the Internet, with $89 \%$ of these preferring to search from a desktop/laptop (Conell et al. 2016).

\section{Wearables}

In 2018, about $20 \%$ of adult Americans used wearable technology at least once a month (Statistica 2019c). Wearable technology refers to accessories and clothing incorporating computer technologies, including smart watches, fitness trackers, smart clothing, and ear-worn devices (Godfrey et al. 2018). Smart watches and fitness trackers are the most popular wearables (Gartner 2018), and sales are growing rapidly (IDC 2019). Wearables are playing an increasing role in healthcare (Amft 2018), including mental health (Behar et al. 2019). Many smartphone apps connect to sensors in wearable technologies (research2Guidance 2018). For example, Abilify MyCite are aripiprazole pills with an embedded sensor that communicates to a wearable patch when ingested, which then transmits data to a smartphone app (FDA 2017a).

\section{Medical apps from the app stores}

The app stores offer trusted one-stop shopping for consumers to obtain software for their smartphone's operating system, few entry barriers for app developers, and instant credibility for small developers (Deloitte 2018). Apple and Google dominate the distribution of apps from their stores. In 2018, there were 2.1 million apps in the Android store and 2 million apps in the Apple store (Statistica 2019a). The number of health apps and health app publishers keeps growing. In 2017, there were 325,000 health apps available from 84,000 health app publishers, with about 78,000 apps added in the last year (research2guidance 2018). The majority of apps are developed by technology companies or app developers outside of the healthcare industry (research2guidance 2016; Ahmed et al. 2018). Most health apps have less than 5000 yearly downloads (research2guidance 2017). The selection of mental health apps available in the app stores is constantly changing. In a 9-month study of apps available in Australian Google Play and Apple iTunes stores related to depression, bipolar disorder and suicide, $50 \%$ of results changed after 4 months with an app being removed every 2.9 days (Larsen et al. 2016b).

\section{App retention rates}

The user retention rate for smartphone apps in the general population is low. About 25\% of users abandon apps after one use (Rodde 2019). For both Android and Apple smartphones, the app retention rate worldwide after 90 days was just 4\% in 2016 (Statistica 2019b). Even the wildly popular Pokémon Go app dropped $80 \%$ of users in a few months (comScore 2017a).

Similarly, reports for health apps, including mental health related, show limited downloads and poor retention, especially outside of clinical trials and research settings. In national surveys in Germany, 20.5\% of adult 
smartphone users 35 years or older, and $16.5 \%$ older adults used a health app (Ernsting et al. 2017; Rasche et al. 2018). In a national survey of smartphone users in the US, 58\% had downloaded a health app but about half had stopped using it (Krebs and Duncan 2015). In other studies using national data, people who used health apps were younger, richer and in excellent health (Carroll et al. 2017), and a heath app was downloaded by $12 \%$ of those with depression (Robbins et al. 2017). In studies of patients with mental illness, a mental health app was downloaded by $10.7 \%$ at a VA facility (Lipschiz et al. 2019). About $10 \%$ of patients both at a state clinic and at a private insurance clinic were using a mental health app (Torous et al. 2018). A review of digital self-help apps or programs for depression and anxiety, involving 8 to 40,000 downloads or registrations per month, reported $21-88 \%$ using at least once, and $0.5-28.6 \%$ continuing after 6 weeks (Fleming et al. 2018). Only 18.7\% of a US Hispanic/Latino population enrolled in a depression clinical trial downloaded the treatment app (Pratap et al. 2018).

Selective use and low retention rates directly affects research. Data collected from apps or social media are generally not representative of the national population, people with mental illness, or of people with a specific condition (Monteith and Glenn 2016). Additionally, with the low retention rates, researchers using a dataset from the same app or social media platform at different times may be investigating different user populations (Althoff 2017).

While some patients will use and benefit from mental health apps, all consumer technologies have selective use and low retention rates. High interest in mental health apps will not automatically lead to high use (Torous et al. 2018). Mental health app retention may be improved by using the app in clinical settings and providing a free smartphone and data plan (Faurholt-Jepsen et al. 2015, 2019; Achtyes et al. 2019). Given that only about 50\% of patients take medications as prescribed (Brown and Bussell 2011), expectations for the use of recommended medical apps should not be overly optimistic.

\section{Selection of mental health apps}

Most consumers find mental health apps through social media, web searches or word of mouth rather than by professional recommendation (Schueller et al. 2018). Smartphone owners often rely on online app reviews but these can be misleading. For example, none of the 25 most popular iPhone apps for anxiety and worry, as indexed by user ratings, included content consistent with evidence-based treatments (Kertz et al. 2017). Users gave high reviews to a very popular but inaccurate blood pressure app that was withdrawn from the market (Plante et al. 2018). Patients and physicians may have a different perspective on the quality or usability of apps (Singh et al. 2016, 2019), including for bipolar disorder (Nicholas et al. 2015). In a study of top ranked mental health apps from Google Play and iTunes stores, scientific language, not direct evidence, was the most frequently employed strategy to support claims of effectiveness (Larsen et al. 2019). Additionally, there are many services for unscrupulous app developers to game the app review process, such as by paying users to write reviews (Hill 2018).

\section{Attitudes towards apps and wearables}

People have varied attitudes towards the use of apps and wearables. Many people with chronic medical illness reject self-monitoring, finding it annoying, depressing, a burden, or prefer to forget they are ill (Lupton 2013; Bauer et al. 2017). The very process of measurement may hinder enjoyment of physical activities and decrease wellbeing (Toner 2018; Etkin 2016). Some may fixate on one measure, such as a step count, and ignore other health related issues (Felde 2019). Patients with mental illness may prefer apps that support relaxation and time management, rather than apps that directly target their disorders (Dragovic et al. 2018). Some feel that the privacy risks associated with wearable devices pose a threat to their health and well-being (Marakhimov and Joo 2017). Some feel they are being increasingly asked to rely on their own observations and online findings, and view this as being outside the traditional healthcare system (Vesnic-Alujevic et al. 2018). Many of the patients who do not use mental health apps may prefer direct, personal contact with a psychiatrist.

\section{Clinical utility}

\section{Issues with regulation of apps and wearables}

In the US, very few medical apps and wearables, including for mental health, require FDA review. Regulation is limited primarily to software that is an accessory to a regulated medical device, or that will transform a mobile platform into a regulated medical device (Davis 2017; FTC 2016). The vast majority of medical apps that pose "minimal risk" to a user are outside of FDA enforcement. For example, mental health apps that help to self-manage but do not claim to diagnose or provide specific treatment suggestions would pose "minimal risk" (FTC 2016; Armontrout et al. 2018). Even with software devices that require FDA review, under the FDA Digital Health Software Pre-certification Program, the manufacturer, not the actual software product, is certified based on a company culture of software quality and commitment to patient safety (Terry 2019). Although post-market surveillance is required, consumers and physicians may not realize that FDA pre-certification does not necessarily 
mean that products were proven safe and effective before release (Lee and Kesselheim 2018). An unforeseen result of this regulatory policy may be the release of consumer products deemed controversial by physicians, such as the use of Apple Watch to detect undiagnosed atrial fibrillation (Mandrola and Foy 2019; Packer 2019; Rowland 2018). Lack of regulation of medical and mental health apps is a growing international problem (Parker et al. 2019).

\section{Measurement accuracy of apps and wearables}

Sensors in smartphones and wearables offer the potential for physiological measurement and remote monitoring (Lowe and Ólaighin 2014). However, measurement inaccuracies are frequently reported including overestimation, underestimation, high variability, misclassification of results, and lack of agreement with gold standards (Hwang 2018). See Tables 1 and 2. Frequent errors are related to properties of the embedded sensors and smartphone hardware, the medical apps, and the human use of smartphones and wearables.
The sensors embedded in smartphones and other consumer devices are generally not professional grade due to manufacturing costs and power requirements, and may be inaccurate (Grewal and Andrews 2010; Puentes et al. 2013; del Rosario et al. 2015; Grammenos et al. 2018). For example, there is sensor bias (defined as the average sensor output at zero sensor input) in the accelerometer and gyroscope, as measured in 61 smartphones including models from Samsung, Apple, Huawei, and Sony (Kos et al. 2016). This bias must be calibrated and compensated for by sensor type and model, especially in apps designed to run across multiple smartphone devices. Additionally, when the same sensor is embedded in a smartphone from a different manufacturer using a different operating system, results may differ since sensor signals are processed by the operating system before being presented to the apps. Apps from different developers, which are based on the same sensor and run on the same device, may also provide different results due to different software programming techniques.

Table 1 Accuracy problems in studies using physiological measurements by smartphone apps

\begin{tabular}{|c|c|c|c|c|c|}
\hline Measure & App & Smartphone & Participants & Finding & Study \\
\hline Blood pressure & Instant Blood Pressure & iPhone 5 and 6. & $\begin{array}{l}85 \text { patients and staff; } \\
\text { 53\% with hyperten- } \\
\text { sion. }\end{array}$ & $\begin{array}{l}\text { Measures "were highly } \\
\text { inaccurate" }\end{array}$ & Plante et al. (2016) \\
\hline Heart rate & $\begin{array}{l}\text { Instant Heart Rate } \\
\text { Heart Fitness } \\
\text { Whats My Heart Rate } \\
\text { Cardio Version }\end{array}$ & iPhone 4 and 5. & $\begin{array}{l}108 \text { patients, exluding } \\
\text { those in critical condi- } \\
\text { tion. }\end{array}$ & $\begin{array}{l}\text { "substantial performance } \\
\text { differences" between } \\
\text { the four apps }\end{array}$ & Coppetti et al. (2017) \\
\hline $\begin{array}{l}\text { Heart rate } \\
\text { Blood pressure } \\
\text { Oxygen saturation }\end{array}$ & $\begin{array}{l}\text { Instant Blood Pressure } \\
\text { Instant Blood Pressure } \\
\text { Pro } \\
\text { Pulse Oximeter } \\
\text { Pulse oximeter Pro }\end{array}$ & iPhone 5S & 100 healthy participants & $\begin{array}{l}\text { "applications evaluated } \\
\text { do not provide clini- } \\
\text { cally meaningful data" } \\
\text { "inaccurate data.. can } \\
\text { potentially contribute } \\
\text { to patient harm" }\end{array}$ & $\begin{array}{l}\text { Alexander et al. } \\
\quad(2017)\end{array}$ \\
\hline Heart rate & $\begin{array}{l}\text { Runtastic Heart Rate } \\
\text { Monitor } \\
\text { Instant heart rate+ }\end{array}$ & iPhone & $\begin{array}{l}15 \text { regularly active col- } \\
\text { lege students }\end{array}$ & $\begin{array}{l}\text { "Poor correlation to ECG" } \\
\text { during moderate to } \\
\text { high intensity exercise }\end{array}$ & Bouts et al. (2018) \\
\hline Step counting & $\begin{array}{l}\text { Argus: calorie counter } \\
\text { and step }\end{array}$ & $\begin{array}{l}\text { Android phones: Sam- } \\
\text { sung, OnePlus, Moto, } \\
\text { Oppo, Galazy, Huawei, } \\
\text { LG, Google, Sony and } \\
\text { Agora running Android } \\
4.4 \text { to } 8.1 \\
\text { Apple: iPhone 6, 6S, 7, 8, } \\
\text { running iOS10.3-11.4. }\end{array}$ & 48 healthy participants & $\begin{array}{l}\text { "extraordinarily large } \\
\text { error ranges for both.. } \\
\text { phones" } \\
\text { "appear unsuitable to } \\
\text { detect steps in short, } \\
\text { slow, or non-stereotyp- } \\
\text { ical gait patterns" }\end{array}$ & Brodie et al. (2018) \\
\hline Sleep & Sleep time & iPhone $4 \mathrm{~s}$ and 5 & $\begin{array}{l}20 \text { participants with no } \\
\text { sleep disorder }\end{array}$ & $\begin{array}{c}\text { "absolute parameters } \\
\text { and sleep staging.... } \\
\text { correlate poorly with } \\
\text { polysomnography" }\end{array}$ & Bhat et al. (2015) \\
\hline Sleep & MotionX 24/7 & iPhone 4 & $\begin{array}{l}78 \text { children and adoles- } \\
\text { cents with suspected } \\
\text { sleep disordered } \\
\text { breathing }\end{array}$ & $\begin{array}{l}\text { "did not accurately reflect } \\
\text { sleep or wake and } \\
\text { should be used with } \\
\text { caution" }\end{array}$ & Toon et al. (2016) \\
\hline
\end{tabular}


Table 2 Accuracy problems in studies using physiological measurements by wearables

\begin{tabular}{|c|c|c|c|c|c|}
\hline Measure & Number tested & Wearables & Patients & Finding & Study \\
\hline $\begin{array}{l}\text { Total energy } \\
\text { expendi- } \\
\text { ture }\end{array}$ & 12 devices & $\begin{array}{l}\text { Withings Pulse } \\
\text { Jawbone } \\
\text { Garmin Vivofit } \\
\text { Suzuken Lifecorder EX } \\
\text { Panasonic Actimaker } \\
\text { Epson Pulsense } \\
\text { Tanita-AM-160 } \\
\text { Fitbit Flex } \\
\text { Misfit Shine } \\
\text { Omron Active Style Pro } \\
\text { Omron CaloriScan }\end{array}$ & 19 healthy adults, not obese. & $\begin{array}{l}\text { "absolute values differed } \\
\text { widely among products and } \\
\text { varied significantly from the } \\
\text { gold standard measures" }\end{array}$ & Murakami et al. (2016) \\
\hline Step count & 3 pedometers & $\begin{array}{l}\text { Yamax } \\
\text { Digiwalker } \\
\text { Fitbit }\end{array}$ & $\begin{array}{l}14 \text { young health participants } \\
\text { walking at } 3 \text { speeds }\end{array}$ & $\begin{array}{l}\text { "all the evaluated devices had } \\
\text { high error rates at } 1 \mathrm{~km} / \mathrm{h} \text { " } \\
\text { (slow walking speeds). }\end{array}$ & Beevi et al. (2016) \\
\hline Step count & 10 activity trackers & $\begin{array}{l}\text { Polar Loop } \\
\text { Garmin Vivosmart } \\
\text { Fitbit Charge HR } \\
\text { Apple Watch Sport } \\
\text { Pebble Smartwatch } \\
\text { Samsung Gear S } \\
\text { Misfit Flash } \\
\text { Jawbone Up Move } \\
\text { Flyfit } \\
\text { Moves }\end{array}$ & $\begin{array}{l}31 \text { healthy participants on a } \\
\text { treadmill }\end{array}$ & $\begin{array}{l}\text { "Test-retest validity depends } \\
\text { on walking speed"; "con- } \\
\text { sumer activity trackers per- } \\
\text { form better at average and } \\
\text { vigorous walking speed..." }\end{array}$ & Fokkema et al. (2017) \\
\hline Sleep & 2 monitors & $\begin{array}{l}\text { Withings Pulse } \\
\text { Jawbone Up }\end{array}$ & $\begin{array}{l}\text { 36, including } 22 \text { with obstruc- } \\
\text { tive sleep apnea (OSA) }\end{array}$ & $\begin{array}{l}\text { "confirmed... in patients suf- } \\
\text { fering from OSA, the limited } \\
\text { performance of wearable } \\
\text { sleep monitors" }\end{array}$ & Gruwez et al. (2019) \\
\hline Sleep & 2 monitors & $\begin{array}{l}\text { Fitbit Change } 2 \\
\text { Neuroon }\end{array}$ & 25 students & $\begin{array}{l}\text { Underestimate light sleep and } \\
\text { overestimate deep sleep. } \\
\text { "Reasonably satisfactory for } \\
\text { general purpose and non- } \\
\text { clinical use" }\end{array}$ & Liang and Martell (2018) \\
\hline
\end{tabular}

The sensors that are embedded in smartphones often change over time, which may lead to varying measurement results. From a manufacturing perspective, all components of a smartphone including sensors may have cost or power saving revisions through a variety of approaches including part substitution (using a different part with identical or similar form, fit and function), and by redesign (upgrading the system to utilize newer parts) (Solomon et al. 2000). As a smartphone goes through its product life cycle, it is very likely that components, including sensors, for the same model have been revised, which may change measured results. Additionally, specific models of smartphones have a short lifespan with new models often introduced yearly. When smartphone models change, it is very likely that hardware components including sensors will change and software must be recalibrated (Li et al. 2010; del Rosario et al. 2015; Kos et al. 2016). The sensors used in wearables also change frequently and will result in inconsistent data collection (Amft and Van Laerhoven 2017).

Hardware features of the smartphone itself can influence measurements including power consumption, processor speed, smartphone size, the position of sensor in the device, and sensor ability to handle noisy indoor and outdoor environmental conditions (Parpinel et al. 2017; Agu et al. 2013; GPS 2017). Individual actions also may impact measurement accuracy such as where and how a smartphone is held (Agu et al. 2013; Vezočnik and Juric 2019), and not following instructions on how to use an app. Patients may forget to charge a smartphone, stop using sensor based apps to preserve battery life, turn off the smartphone, be out of range for data transmission, or loan the phone to another person (Agu et al. 2013; Boonstra et al. 2018). Similar problems also occur with wearables. A review of 67 studies of Fitbit devices found that other than measures of steps in adults without mobility limitations, the device is unlikely to provide sufficiently accurate measurement for clinical medicine or research (Feehan et al. 2018).

The various revisions of sensors and models for the smartphone and other devices are of major concern since the vast majority of apps are not regulated by the FDA as a medical device. A traditional medical device would 
require testing, validation and recertification by a regulatory body after a hardware or software change that may be critical to safety or efficacy, before the modified device is released to the public (FDA 2017b).

\section{Blue light exposure}

Measurement using smartphone apps and small devices is also a concern because light-emitting diode (LED) backlights are used to enhance daytime brightness and contrast of displays (Gringras et al. 2015; Oh et al. 2015). Unlike conventional lighting, LEDs emit bright blue light at a wavelength close to the peak sensitivity for non-visual circadian photoreception (Gringras et al. 2015; Oh et al. 2015). In studies primarily of healthy volunteers, exposure to blue light may disrupt a variety of circadian functions (Tosini et al. 2016; Bauer et al. 2018b), even at low intensities (Prayag et al. 2019). For example, even "nighttime" settings on devices may emit light far above the predicted threshold for melatonin suppression (Prayag et al. 2019). When a smartphone is used as a measuring device, exposure to blue light can directly impact the patient and influence the measurement of a wide range of variables including alertness, cognition, sleep, and activity levels. Without understanding if exposure to blue light from smartphones, other devices, or ambient lighting is impacting what is being measured, data collected are difficult to interpret (Bauer et al. 2018b).

\section{Efficacy not proven}

A lack of efficacy of smartphone apps and wearables extends throughout medicine. A Cochrane review of automated telephone communication systems, often smartphone based, included 132 clinical trials and over 4 million participants across specialties (Posadzki et al. 2016). Positive effects were found from reminders, including increased prevention screenings and appointment attendance, while other effects varied by condition with "little or no effect" in mental health (Posadzki et al. 2016; Foster and Callans 2017). Table 3 summarizes systematic reviews of apps related to mental health that are available to consumers. While many studies discuss the potential of mental health apps, there is little clinically validated evidence. For example, a review of 100 studies that used a mental health app for a wide range of conditions, only 14 had clinically validated evidence (Wang et al. 2018). Additionally, reviews that focus on the mental health apps with controlled trials generally have conclusions such as promising but little evidence today, studies of mixed quality, and more, larger trials needed (Dogan et al. 2017; Byambasuren et al. 2018; Firth and Torous 2015; Wang et al. 2018). However, given the low cost of entry for app developers, the vast majority will never be able to afford even a simple clinical trial to establish efficacy (Foster and Callans 2017). This is a major challenge: how do we test the effectiveness of these applications in a timely, robust and cost-effective manner? Are clinical trials always necessary? Answering these questions is critical and will need considerable methodological innovation.

\section{Passive monitoring}

Some apps focus primarily on using a smartphone for ongoing passive monitoring of individuals with mental illness. Passive monitoring collects data from patients without requiring direct patient input, often using only sensors to measure a wide range of variables such as activity level, mobility, physiological measures, speech patterns, and signals of social interactions (Abdullah and Choudhury 2018). Reviews of passive monitoring report similar conclusions, that results are promising but many methodological and interpretive challenges remain, larger trials are needed, and evidence in clinical settings is lacking (Faurholt-Jepsen et al. 2018; Cornet and Holden 2018; Seppälä et al. 2019; Rohani et al. 2018; Goodday and Cipriani 2019). In addition to the hardware and software concerns, there are special concerns with passive monitoring related to stigma and privacy (Bauer et al. 2017). Of patients interested in apps, a significant minority does not want to be monitored and tracked or provide private sensor-based data (Thornton and Kay-Lambkin 2018; Klasnja et al. 2009; Torous et al. 2018; Ben-Zeev et al. 2016; Di Matteo et al. 2018; Hendrikoff et al. 2019). In a study of mobile sensing of 126 adults with depression recruited from the general public in Switzerland, half uninstalled the app within 2 weeks (Wahle et al. 2016). Mood assessment by passive monitoring was not useful at the population level (Pratap et al. 2019). Patient adherence with wearables is also a major problem (Amft 2018).

\section{Ethical issues with mental health apps}

There are many ethical issues associated with mental health apps. Apps are being widely promoted, often containing incorrect information and with unproven efficacy. See Tables 1, 2 and 3. Mental health apps may promote unsafe and misleading messages. For example, potentially harmful information was noted in apps about bipolar disorder (Nicholas et al. 2015), suicide (Larsen et al. 2016a) and alcohol use (Crane et al. 2015). A study of 64 frequently used mental health apps noted two recurring themes: that fragile mental health is ubiquitous, and that individuals can easily manage mental health problems with apps (Parker et al. 2018). These messages may medicalize normal mental states, and be dangerous for those with diagnosed mental illness who need a clear 


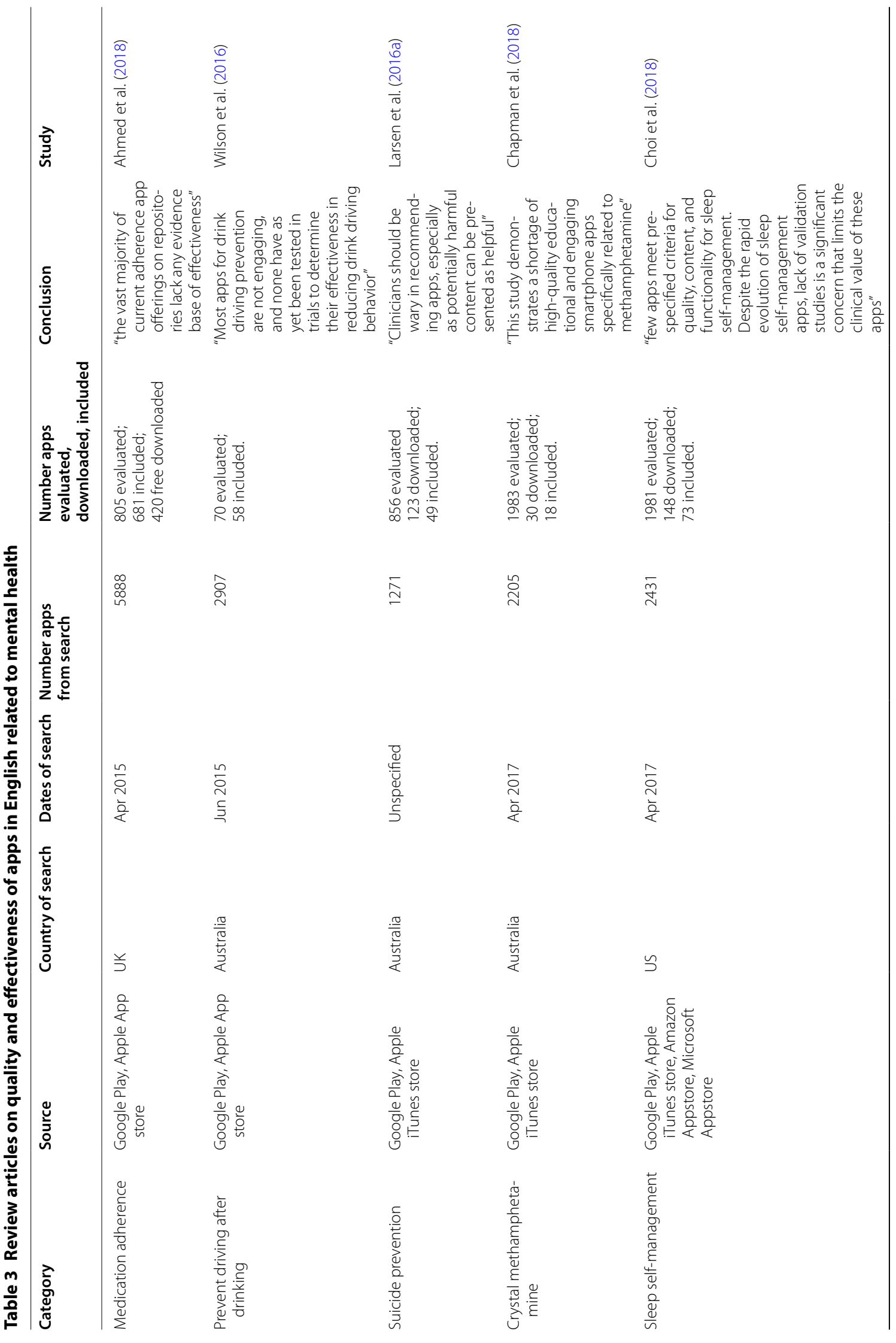




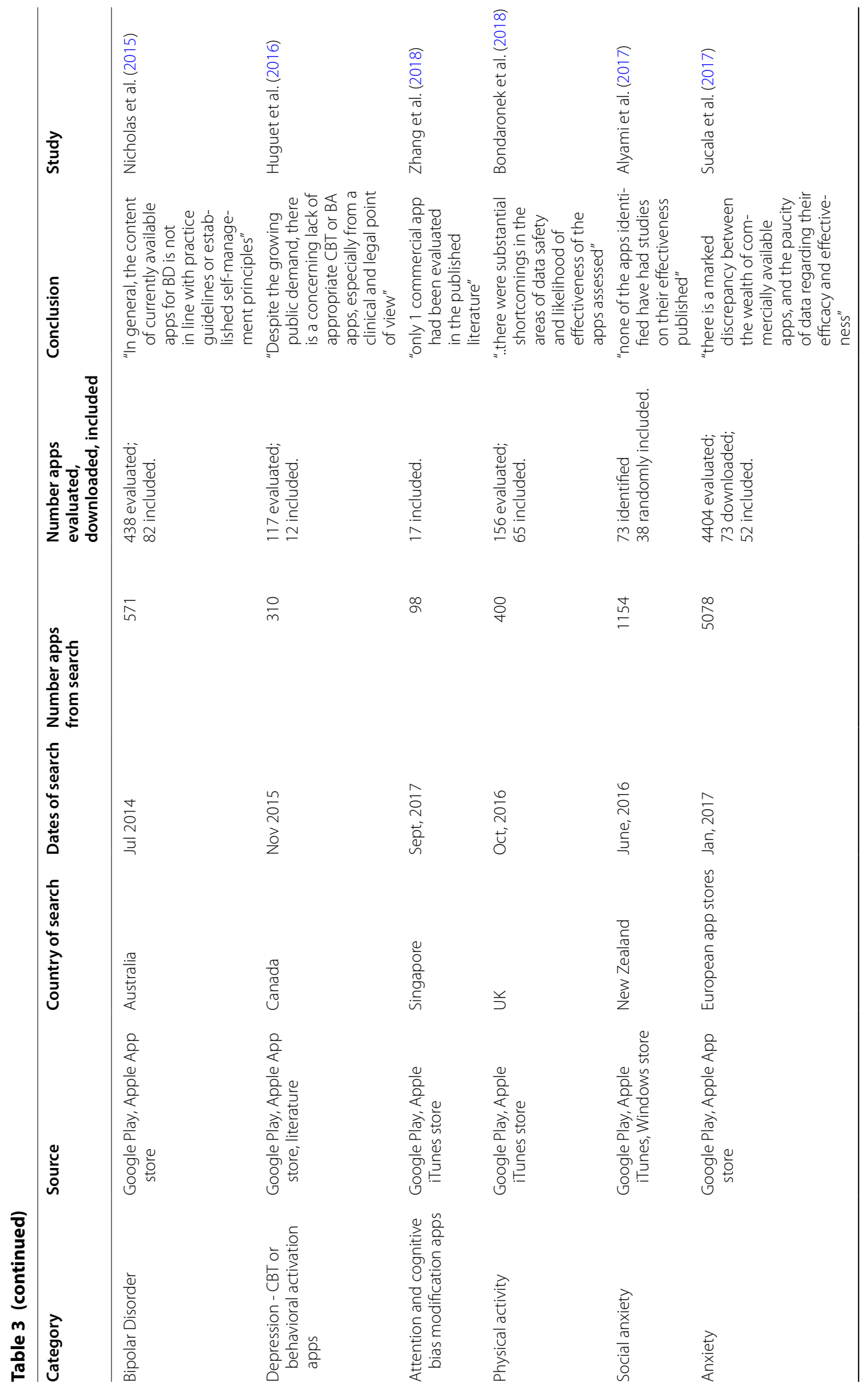




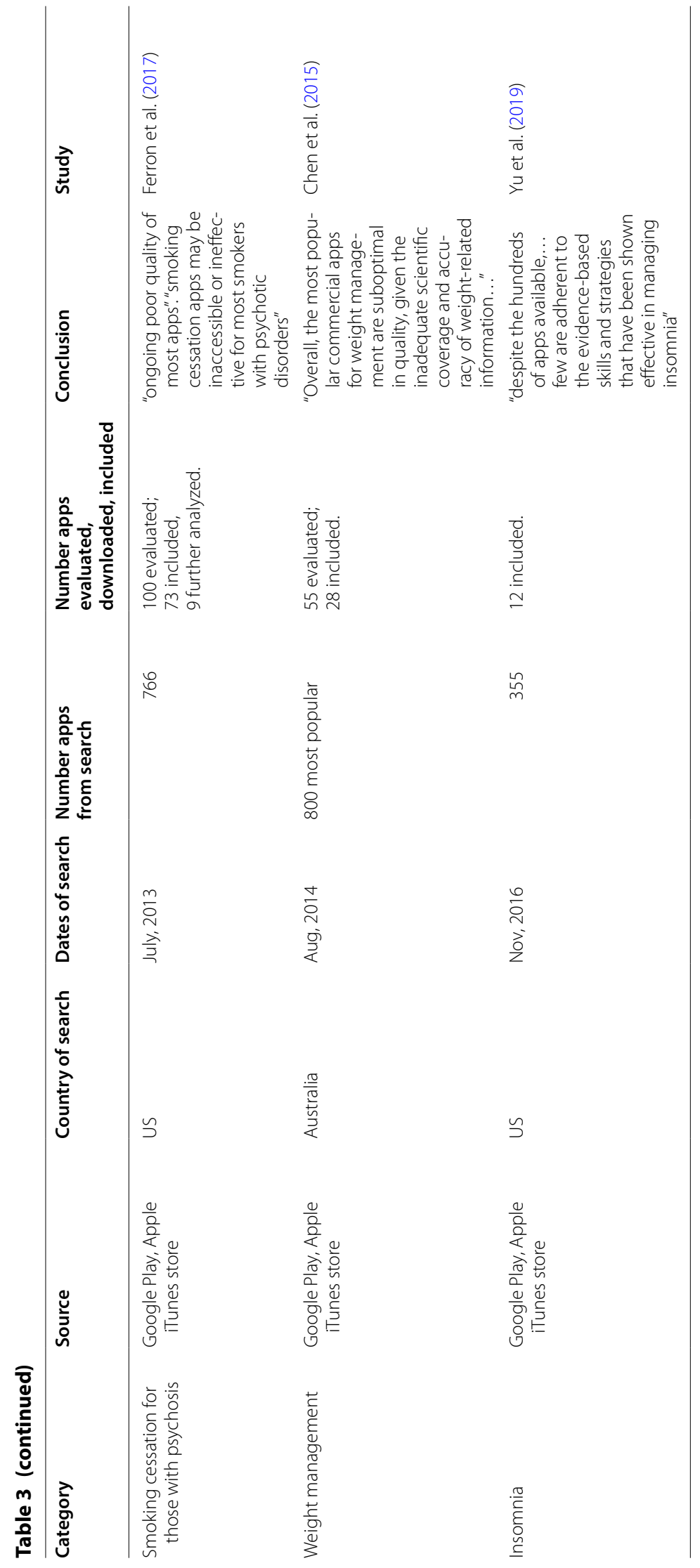


understanding of when to seek professional help (Parker et al. 2018). Problematic use of smartphones is associated with depression and anxiety, and mental health apps may not be appropriate (Elhai et al. 2017; Kim et al. 2015). Lax regulation may allow direct-to-consumer psychotherapy apps to connect users to minimally trained, nonprofessional counselors (Martinez-Martin and Kreitmai 2018). Apps that connect patients to chatbots may provide incomplete responses to simple questions, have limited capacity to recreate human interactions or offer tailored treatment, and may not provide real time access to mental health services when needed (Kretzschmar et al. 2019; Miner et al. 2016).

Another issue relates to recommending apps to patients without sufficient understanding of the patient's technical competence, awareness of privacy issues, and ability to avoid online harm (Bauer et al. 2017; Torous and Roberts 2017; Gangadharan 2017). Poor digital skills, lack of knowledge of online safety practices, individual traits associated with mental illness, and cognitive impairment all increase vulnerability to online fraud (Monteith and Glenn 2016; Gangadharan 2017; Sheng et al. 2010; Bauer et al. 2017, 2018a).

\section{Commercialization}

\section{Commercial firms and the digital economy}

As commercial firms play an increasing role in providing apps, wearables, and algorithms in medicine, it is important to recognize that the digital economy is based on collecting and selling personal data (Bauer et al. 2017). The dominant business model depends on violating privacy (Narayanan 2018) as commercial firms routinely track all individual online activities and habits (Glenn and Monteith 2014a; Monteith and Glenn 2016). Data are collected, combined with other data, and re-sold as data products. This commodification of consumer data includes data from medical apps and wearables, facial recognition, as well as biometrics used in authentication schemes (Elvy 2018; Roberts 2019). With this distributed and redundant data economy, one should assume that data cannot be permanently deleted (PCAST 2014).

Commercial, academic and governmental organizations purchase data, combine data with other data from all aspects of daily life, and create algorithms that are routinely used to classify people (Bauer et al. 2017; Monteith and Glenn 2016). The use of these classifications extends far beyond behavioral or personalized advertising, and sales of products "recommended for you" (Beales 2010). These algorithm classifications directly impact almost every aspect of daily life, including education, employment, credit, healthcare, criminal justice, and government services (Monteith and Glenn 2016; Bauer et al. 2017). In the US, the market value of personal data was estimated at $\$ 76$ billion in 2018, increasing $44.9 \%$ from 2016 to 2018 (Shapiro and Aneja 2019). Most commercial algorithms are proprietary and opaque, with this lack of transparency posing a variety of safety dangers (Bauer et al. 2019; ACM 2017; AI HLEG 2019). Despite the size, the big data basis for the classification may not be representative of the general population, or of those with mental illness (Monteith et al. 2016). Algorithmic decision-making based on big data may be incorrect, reflect human biases, and incorporate and perpetuate traditional social prejudices and stigmas (Monteith and Glenn 2016; Executive Office 2016; Partnership on AI 2019; AI HLEG 2019).

\section{Individual discomfort with the digital economy}

There is a major disconnect between corporate and individual perspectives on the use of personal digital data. In a 2018 survey of adults in US, France, UK and Germany, $75 \%$ now limit the personal information they share online, only $29 \%$ feel that providing data leads to better commercial products and services, and $60 \%$ found wearables "creepy" (RSA 2019). In a 2018 survey of adults in the US, only $11 \%$ were willing to share health data with technology companies (Day and Zweig 2019). In a 2018 survey of US Facebook users, 74\% were unaware Facebook was classifying them, $51 \%$ were uncomfortable with this and $27 \%$ said the classifications were inaccurate (Hitlin and Rainie 2019). In another 2018 survey in the US, about $60 \%$ thought algorithmic decision-making was unfair and that computer programs will always reflect human bias (Smith 2018). In a survey in Germany, users completely rejected sharing mental health information with commercial organizations for developing health recommender systems (Valdez and Ziefle 2019).

\section{Privacy protection}

Patients are very concerned about privacy (Torous et al. 2018), and many are not comfortable providing personal data to clinicians via mobile apps (Dragovic et al. 2018). In the US, most apps fall outside of HIPAA protections, which only apply to traditional healthcare relationships and environments including healthcare providers, insurers and their business associates (Cohen and Mello 2018; Gostin et al. 2018). HIPAA does not cover patient-generated data from apps, wearables or the Internet, which is collected by firms and services that receive, store, combine, analyze and sell the data (Cohen and Mello 2018; Glenn and Monteith 2014b; Monteith and Glenn 2016; Gostin et al. 2018). HIPAA also does not cover the diverse range of non-medical digital data that is routinely included in medically related algorithms (Glenn and Monteith 2014b). HIPAA does apply when data from 
apps or wearables are sent to the EMR (Hughes 2019; MicroMD 2019). Although the European GDPR requires more robust accountability, some firms circumvent these rules as the data environment becomes increasingly internationalized (Gostin et al. 2018; Vinokur 2019; Scott et al. 2019).

\section{Privacy policies}

For most smartphone apps and wearables, the only protections provided to users are those included in the privacy policy. The requirement for apps to a provide privacy policy is increasing, but varies internationally and by app store. Studies that searched for apps after 2016 found that many lacked a privacy policy, as shown in Table 4. Based on a "notice and consent" model, a privacy policy offers the consumer a take-it-or-leave it choice to agree to the terms (PCAST 2014). Most people just agree without reading privacy policies, which are often unclear, written at a post-secondary level with technical information embedded in legal language (PCAST 2014; Frazee et al. 2016; Robillard et al. 2019). Privacy policies for apps and wearables routinely authorize the sale, transfer, analysis and disclosure of consumer data to third parties (Elvy 2018). For example, an analysis of network traffic and privacy policies of top rated Android apps for prescription medications in Oct-Nov 2017, found that 19 of 24 apps (74\%) shared data with 55 unique third parties, who in turn could share with 216 fourth parties (Grundy et al. 2019). The companies receiving this data included large tech companies, Alphabet/Google, Facebook and Oracle, and digital advertising firms, among others. In an analysis of the 36 top-ranked apps for depression and smoking cessation in Jan 2018, 33 of the 36 apps (92\%) shared data with a third party, and 29 of the 36 apps (81\%) shared data with Google and Facebook (Huckvale et al. 2019). Most privacy policies authorize the sale of personal data in the case of a merger, acquisition or bankruptcy (Elvy 2018, Singer and Merrill 2015). This is pertinent since in the US about $90 \%$ of all business startups fail (Patel 2015), including 3 out of 4 venture backed firms (Gage 2012). Additionally, patterns detected in the analysis of large, diverse datasets may allow firms to infer medical conditions and thus undermine the importance of individual consent (Barocas and Nissenbaum 2014).

\section{Security issues for app or wearable data in EMR}

As more data from patient apps are sent to the EMR, procedures must be in place to safely handle the data influx.

Table 4 Studies of percent of apps searched 2016-2018 that provide a privacy policy

\begin{tabular}{|c|c|c|c|c|c|c|}
\hline App search & Source & Dates of search & Country of search & Number of apps & $\begin{array}{l}\text { Percent } \\
\text { with privacy } \\
\text { policy (\%) }\end{array}$ & Study \\
\hline Depression & $\begin{array}{l}\text { Google Play, Apple } \\
\text { iTunes store }\end{array}$ & Oct, 2017 & US & 116 & $49 \%$ & $\begin{array}{l}\text { O'Loughlin et al. } \\
\text { (2019) }\end{array}$ \\
\hline Depression & $\begin{array}{l}\text { Google Play, Apple } \\
\text { App store }\end{array}$ & Oct-Nov, 2018 & UK & 353 & $74 \%$ & $\begin{array}{l}\text { Bowie-DaBreo et al. } \\
2019\end{array}$ \\
\hline $\begin{array}{l}\text { Depression and } \\
\text { smoking cessation }\end{array}$ & $\begin{array}{l}\text { "official Android and } \\
\text { iOS marketplaces" }\end{array}$ & Jan, 2018 & US and Australia & 36 & $69 \%$ & Huckvale et al. (2019) \\
\hline "mood" and "track" & $\begin{array}{l}\text { Google Play, Apple } \\
\text { App store }\end{array}$ & $\begin{array}{l}\text { Jun-Aug, 2016; } \\
\text { and Jan-Feb } \\
2017^{a}\end{array}$ & Canada & $\begin{array}{l}319 \text { IOS; } \\
69 \text { Android }\end{array}$ & $\begin{array}{l}18 \% \text { for } 105 ; 4 \% \\
\text { Android }^{b}\end{array}$ & Robillard et al. (2019) \\
\hline Dementia & $\begin{array}{l}\text { Apple iTunes } \\
\text { store }\end{array}$ & Apr-May, 2016 & US & 72 & $46 \%$ & Rosenfeld et al. (2017) \\
\hline $\begin{array}{l}\text { Specific diseases } \\
\text { including mental } \\
\text { illnesses }\end{array}$ & $\begin{array}{l}\text { Google Play, Apple } \\
\text { iTunes store }\end{array}$ & July 2018 & US & $\begin{array}{l}40 \text { each for anxiety, } \\
\text { schizophrenia, } \\
\text { depression, } \\
\text { addiction }\end{array}$ & $\begin{array}{l}\text { 85\%-anxiety; } \\
\text { 50\%-schizophre- } \\
\text { nia; 85\%-depres- } \\
\text { sion; } \\
\text { 70\%-addiction }\end{array}$ & $\begin{array}{l}\text { Wisniewski et al. } \\
\text { (2019) }\end{array}$ \\
\hline Migraine & $\begin{array}{l}\text { Google Play, Apple } \\
\text { App store, health- } \\
\text { line.com }\end{array}$ & July-Aug, 2017 & US & 29 & $76 \%$ & Minen et al. (2018) \\
\hline Mental Health & Google Play & May-Jun, 2017 & India & $82^{c}$ & $35 \%$ & Powell et al. (2018) \\
\hline $\begin{array}{l}\text { Increase physical } \\
\text { activity }\end{array}$ & $\begin{array}{l}\text { Google Play, Apple } \\
\text { iTunes store }\end{array}$ & Oct, 2016 & UK & 65 & $70 \%$ & $\begin{array}{l}\text { Bondaronek et al. } \\
\text { (2018) }\end{array}$ \\
\hline
\end{tabular}

Apps in English

a Personnel communication

b Terms of agreement present for 15\% of Apple and 3\% of Android

c Apps in English of Indian origin 
The healthcare industry is a frequent target of all forms of cyberattacks due to extreme vulnerability to disruption in services, and the ability for criminals to monetize the financial and health information contained in medical records (Argaw et al. 2019). These cyber attacks occur worldwide with major incidents reported in the US, UK and Norway (Charette 2018). In the US, data breaches increased between 2010 and 2017 and involved 176.4 million patient medical records (McCoy and Perlis 2018). Ransomware is increasing rapidly (DOJ 2017), with healthcare the most targeted industry (Donovan 2018). Patient portals into EMR have also been compromised (HIPAA Journal 2017). The 2017 US Health Care Industry Cybersecurity Task Force concluded that healthcare cybersecurity is in "critical condition" (HHS 2017). Yet IT spending as a percentage of revenue is much lower in healthcare compared with financial services, another industry that must focus on security (Computer Economics 2019). This is illustrated when considering the IT spending per user, including both employees and non-employees, based on spending at the 25th and 75th percentiles. IT spending per user at the 25th percentile in financial services is $\$ 13,772$, more than double that of healthcare at the 75 th percentile at $\$ 6143$ (Computer Economics 2019). Lower spending on IT in healthcare than financial services directly impacts security. Even if healthcare and financial services spend the same percentage of the IT budget on security, the dollar amount available in healthcare to obtain expensive IT security products and services is much lower (Computer Economics 2019).

Individual discomfort with app and wearable data in EMR Patient security concerns about EMR may impact disclosure of personal information (Agaku et al. 2014), use of patient portals, and use of apps or wearables that send data to an EMR. In US national surveys, about half the people had concerns about privacy and security of medical records (Patel et al. 2016), and 25\% of those offered a patient portal would not use due to privacy concerns (Patel and Johnson 2018). In a survey of 12,000 adults, nearly all were concerned that sensitive data such as mental health notes would be shared beyond their chosen provider (Snell 2017). Also in this survey, 89\% of patients withheld information, with $93 \%$ of these saying the reason was concerns over security of personal financial information. Between 31 and 38\% of those surveyed in Canada and the UK said they would postpone seeking care due to privacy concerns (Fair Warning 2011a, b).

\section{Evolving consumer technology}

While we are currently in a technology era dominated by smartphones, this will not last. As predicted by Gordon Bell, leader of the minicomputer revolution at Digital Equipment Corporation, a new class of smaller computers is developed about every decade (Bell 2008). The primary computing platform has evolved from mainframes to minicomputers, to workstations, to PCs, to laptops, to smartphones. For over 50 years, the basis for this change was the doubling of the number of transistors per chip about every 2 years as predicted by Gordon Moore, cofounder of Intel (Moore 2006; Mack 2011). The computing platform will continue to evolve beyond smartphones with each new class being smaller and less expensive (Bell 2008). Indeed, mobile subscription sales are near saturation in the developed world (GSMA 2018a), and smartphone sales have reached a plateau and started to decline (Savov 2019; Swearingen 2018).

In the future, apps will be controlled by voice. Voice interfaces to small, smart wearables including watches, fitness trackers, and ear-pads, are coming soon, as well as to smartphone apps, and a wide range of smart devices and home controls (Koetsier 2019). Miniaturized system components, including sensors and microprocessors with greatly reduced power and energy requirements, and new soft, flexible materials will enable ubiquitous sensing and computing (Lee and Lee 2017; Herbert et al. 2018). Voice assistants marketed today include Amazon Alexa, Google Assistant, Apple Siri, and Microsoft Cortana. The number of voice assistants in use worldwide is estimated to triple to 8 billion by 2023 becoming an $\$ 80$ billion market (Perez 2019), while smart wearable device sales will double to 233 million units by 2022, becoming a $\$ 27$ billion market (Lamkin 2018). Consumer electronics shows are dominated by a wide range of voice activated products including TVs, toilets, lightbulbs, ovens, blinds, speakers and showers (Wiggers 2019). The complex issues of privacy, security and commercial involvement, accuracy and efficacy are increasing as consumer devices evolve.

These new voice-activated devices are predicted to replace many of the functions of today's smartphone, and provide new functions that change how we live. In the words of Google CEO Sundar Pichai "Looking to the future, the next big step will be for the very concept of the "device" to fade away. Over time, the computer itself-whatever its form factor-will be an intelligent assistant helping you through your day" (Google 2016). The pace of adaption of new technologies has greatly accelerated, as it took 85 years for a telephone to become an integral part of life and only 13 years for a smartphone (Irving 2019). People will live with an increasing variety of technology products, and the patterns of usage of current devices such as smartphones will change. 


\section{Limitations of this review}

There are limitations to this review. This is not a systematic review of mental health related studies using smartphones apps. Physician perspectives about recommending technology, or the potential impacts of large amounts of patient data in the EMR on physician overload were not discussed. Measures related to improving the usability of apps, and long-term impacts of app use on patient trust were not included. Approaches to rating or recommending apps, legal issues related to app or technology errors, detailed regulatory issues, and technical issues related to privacy, security, and interoperability standards were not discussed. Methodological issues related to the analysis of patient generated data, such as missing values, were not discussed. The requirement to engage in self-tracking outside of medicine, as by employers or insurers, was not discussed. Issues related to anonymization and re-identification of data, and sharing of research data collected from apps, were omitted. Finally, issues related to radiofrequency microwave radiation exposure were not discussed, including cellphone safety limits, emissions when cellphones touch the body, increased absorption rates in children (Gandhi et al. 2012; Gandhi 2019; Fernández et al. 2018; Morris et al. 2015), and potential health effects from long-term exposure (Lin 2018). The article search for this review occurred between February-May, 2019.

\section{Conclusions}

The issues discussed in this paper suggest some recommendations for the future of consumer use of technology in psychiatry.

\section{Maximize patient choice of technology}

The focus of technology in psychiatry should be on automating functions that will allow patient input or contact using many types of consumer technologies, respecting the patient's lifestyle, budget and skill set. For example, those who can only afford intermittent smartphone service may prefer to receive emails rather than text messages (Alcaraz et al. 2018). It is also important to consider that people of all ages with disabilities, including visual or motor impairments, may prefer to use technology other than a smartphone (Watanabe et al. 2015; Trewin et al. 2013; Bauer et al. 2018a). Patient technologies for medicine, including mental illness, should not exclude those with physical disabilities (Wolbring and Lashewicz 2014).

The era of personalized medicine should recognize that patients use and prefer different types of consumer technologies. A medication reminder system could send text messages to a smartphone or feature phone, email to a laptop, call a standard telephone, or connect with a voice assistant. In a US national sample, the most commonly used health technology in 2018 (by 59\%) was to refill prescriptions (Abrams and Korba 2018), which would not require a smartphone. Due to the many limitations discussed above, analyses based on patient data should support many types of technologies, rather than focusing on unregulated, sensor based measurements. A small amount of data could be entered from all commonly used consumer technologies, at a frequency such as daily or weekly.

\section{Help to improve digital skills}

A secondary benefit of recommending the use of technology to those with mental illness is to increase digital skills, and the use of multiple consumer technologies should be encouraged and supported. Some researchers feel that smartphone only access to the Internet is creating a new type of "mobile underclass" with fewer digital skills and more passive online involvement (Napoli and Obar 2014). Studies from diverse countries including The Netherlands and Chile report less information seeking, active participation and variety of Internet use when access is only by smartphone (van Deursen and van Dijk 2019; Correa et al. 2018). In a US study of smartphone users over age $18,87 \%$ of smartphone time was spent on apps and only $13 \%$ on the Internet (ComScore 2017b). Programs to help community integration of those with serious mental illness could include training on the safe use of technology.

\section{Recommendations for the future}

Increased understanding of the complex issues surrounding consumer technologies is needed to successfully integrate apps into the practice of psychiatry. New methodologies must be defined and standardized to evaluate the efficacy of apps used for screening or treatment. Regardless of the technology platform, only some patients will use the app. Given the realities of app accuracy, efficacy, privacy, security, and the regulatory environment, and to maximize participation, a variety of technology platforms should be used for data collection rather than focusing on smartphones. Development should also include administrative apps that may increase care participation, and apps that educate about mental illness. App development requires multidisciplinary expertise in medical, legal, consumer, and technical areas, with physicians and patients heavily involved in all phases, and large-scale testing in clinical settings.

Complete security information should be provided to patients before recommending any apps on any technology platform. Training and ongoing support from humans should be available for all recommended apps. Patients should be allowed to choose if they want their app data included in their EMR, shared with anyone 
other than their psychiatrist, or used in research. Patient data from apps should not be transferred into EMR if insufficient IT resources are available to handle securely, or if unable to accommodate patient choice as to access and use. Finally, investment in programs to increase competence and comfort with technology for those with mental illness should be considered.

\section{Acknowledgements}

None.

\section{Authors' contributions}

MB and TG completed the initial draft of the manuscript, which was reviewed by all authors. All authors read and approved the final manuscript.

\section{Funding \\ None.}

\section{Ethics approval and consent to participate}

Not applicable.

\section{Consent for publication}

The authors provide consent for publication.

\section{Competing interests}

JG reports grants from UK Medical Research Council, grants from Wellcome, grants from National Institute for Health Research, outside the submitted work; and led the conception of True Colours, a digital phenotyping and outcome assessment tool and has overseen its implementation in routine clinical practice and research studies. He is also a National Institute for Health Research Senior Investigator and Director of the NIHR Oxford Health Biomedical Research Centre. LVK has been a consultant for Lundbeck within the last 3 years. The other authors report no competing interests.

\section{Author details}

${ }^{1}$ Department of Psychiatry and Psychotherapy, University Hospital Carl Gustav Carus, Medical Faculty, Technische Universität Dresden, Fetscherstr. 74, 01307 Dresden, Germany. ${ }^{2}$ ChronoRecord Association, Fullerton, CA, USA. ${ }^{3}$ Department of Psychiatry, University of Oxford, Warneford Hospital, Oxford, UK. ${ }^{4}$ Department of Psychiatry and Biobehavioral Sciences, Semel Institute for Neuroscience and Human Behavior, University of California Los Angeles (UCLA), Los Angeles, CA, USA. ${ }^{5}$ Mood Disorders Center of Ottawa, Ottawa, Canada. ${ }^{6}$ Department of Psychiatry, University of Toronto, Toronto, ON, Canada. ${ }^{7}$ Copenhagen Affective Disorder Research Center (CADIC), Psychiatric Center Copenhagen, Rigshospitalet, Copenhagen, Denmark. ${ }^{8}$ Michigan State University College of Human Medicine, Traverse City Campus, Traverse City, $\mathrm{MI}$, USA.

Received: 26 July 2019 Accepted: 24 October 2019

Published online: 10 January 2020

\section{References}

Abdullah S, Choudhury T. Sensing technologies for monitoring serious mental illnesses. IEEE Multimedia. 2018;25:61-75.

Abrams K, Korba C. Consumers are on board with virtual health options. Deloitte Insights. 2018. https://www2.deloitte.com/insights/us/en/ industry/health-care/virtual-health-care-consumer-experience-surve y.html. Accessed 14 June 2019.

Abu Rahal Z, Vadas L, Manor I, Bloch B, Avital A. Use of information and communication technologies among individuals with and without serious mental illness. Psychiatry Res. 2018;266:160-7.

Achtyes ED, Ben-Zeev D, Luo Z, Mayle H, Burke B, Rotondi AJ, et al. Off-hours use of a smartphone intervention to extend support for individuals with schizophrenia spectrum disorders recently discharged from a psychiatric hospital. Schizophr Res. 2019;206:200-8.
ACM. USACM Issues statement on algorithmic transparency and accountability. 2017. https://www.acm.org/binaries/content/assets/public-polic y/2017_joint_statement_algorithms.pdf. Accessed 14 June 2019.

Agaku IT, Adisa AO, Ayo-Yusuf OA, Connolly GN. Concern about security and privacy, and perceived control over collection and use of health information are related to withholding of health information from healthcare providers. J Am Med Inform Assoc. 2014;21:374-8.

Agu E, Pedersen P, Strong D, Tulu B, He Q, Wang L, et al. The smartphone as a medical device: assessing enablers, benefits and challenges. In: 2013 IEEE international workshop of internet-of-things networking and control (IoT-NC). IEEE; 2013 Jun 24. pp. 48-52.

Ahmed I, Ahmad NS, Ali S, Ali S, George A, Saleem Danish H, et al. Medication adherence apps: review and content analysis. JMIR Mhealth Uhealth. 2018;6:e62.

Al HLEG. (EU High-Level Expert Group on Artificial Intelligence). Ethics guidelines for trustworthy Al. 2019. https://ec.europa.eu/digital-single-marke t/en/news/ethics-guidelines-trustworthy-ai. Accessed 14 June 2019.

Alcaraz Kl, Riehman K, Vereen R, Bontemps-Jones J, Westmaas JL. To text or not to text? technology-based cessation communication preferences among urban, socioeconomically disadvantaged smokers. Ethn Dis. 2018;28:161-8.

Alexander JC, Minhajuddin A, Joshi GP. Comparison of smartphone application-based vital sign monitors without external hardware versus those used in clinical practice: a prospective trial. J Clin Monit Comput. 2017:31:825-31.

Althoff T. Population-scale pervasive health. IEEE Pervasive Comput. 2017;16:75-9.

Alyami M, Giri B, Alyami H, Sundram F. Social anxiety apps: a systematic review and assessment of app descriptors across mobile store platforms. Evid Based Ment Health. 2017;20:65-70.

Amft O. How wearable computing is shaping digital health. IEEE Pervasive Comput. 2018;17:92-8.

Amft O, Van Laerhoven K. What will we wear after smartphones? IEEE Pervasive Comput. 2017;16:80-5.

Anderson M, Perrin A. Tech adoption climbs among older adults. Pew Research Centre. 2017. http://www.pewinternet.org/2017/05/17/tech-adoptionclimbs-among-older-adults/. Accessed 14 June 2019.

Argaw ST, Bempong NE, Eshaya-Chauvin B, Flahault A. The state of research on cyberattacks against hospitals and available best practice recommendations: a scoping review. BMC Med Inform Decis Mak. 2019;19:10.

Armontrout JA, Torous J, Cohen M, McNiel DE, Binder R. Current regulation of mobile mental health applications. J Am Acad Psychiatry Law. 2018;46:204-11.

Barocas S, Nissenbaum H. Big data's end run around procedural privacy protections. Commun ACM. 2014;57:31-3.

Bauer M, Glenn T, Monteith S, Bauer R, Whybrow PC, et al. Ethical perspectives on recommending digital technology for patients with mental illness. Int J Bipolar Disord. 2017;5:6.

Bauer R, Glenn T, Strejilevich S, Conell J, Alda M, Ardau R, et al. Internet use by older adults with bipolar disorder: international survey results. Int J Bipolar Disord. 2018a;6:20.

Bauer M, Glenn T, Monteith S, Gottlieb JF, Ritter PS, Geddes J, et al. The potential influence of LED lighting on mental illness. World J Biol Psychiatry. 2018b;19:59-73.

Bauer M, Monteith S, Geddes J, Gitlin MJ, Grof P, Whybrow PC, et al. Automation to optimise physician treatment of individual patients: examples in psychiatry. Lancet Psychiatry. 2019;6:338-49.

Beales H. The value of behavioral targeting. Netw Adv Initiat. 2010;1:1.

Beevi FH, Miranda J, Pedersen CF, Wagner S. An evaluation of commercial pedometers for monitoring slow walking speed populations. Telemed J E Health. 2016;22:441-9.

Behar JA, Oster J, De Vos M, Clifford GD. Wearables and mHealth in mental health and neurological disorders. Physiol Meas. 2019:40:070401.

Bell G. Bell's law for the birth and death of computer classes: a theory of the computer's evolution. IEEE Solid-State Circ Soc Newsl. 2008;13:8-19.

Ben-Zeev D, Wang R, Abdullah S, Brian R, Scherer EA, Mistler LA, et al. Mobile behavioral sensing for outpatients and inpatients with schizophrenia. Psychiatr Serv. 2016;67:558-61.

Berenguer A, Goncalves J, Hosio S, Ferreira D, Anagnostopoulos T, Kostakos V. Are Smartphones Ubiquitous?: an in-depth survey of smartphone adoption by seniors. IEEE Consum Elect Magaz. 2017;6:104-10. 
Bhat S, Ferraris A, Gupta D, Mozafarian M, DeBari VA, Gushway-Henry N, et al. Is there a clinical role for smartphone sleep apps? Comparison of sleep cycle detection by a smartphone application to polysomnography. J Clin Sleep Med. 2015;11:709-15.

Bondaronek P, Alkhaldi G, Slee A, Hamilton FL, Murray E. Quality of publicly available physical activity apps: review and content analysis. JMIR Mhealth Uhealth. 2018:6:e53.

Boonstra TW, Nicholas J, Wong QJ, Shaw F, Townsend S, Christensen H. Using mobile phone sensor technology for mental health research: integrated analysis to identify hidden challenges and potential solutions. J Med Internet Res. 2018;20:e10131.

Bouts AM, Brackman L, Martin E, Subasic AM, Potkanowicz ES. The accuracy and validity of ios-based heart rate apps during moderate to high intensity exercise. Int J Exerc Sci. 2018;11:533-40.

Bowie-DaBreo D, Sunram-Lea SI, Sas C, lles-Smith H. A content analysis and ethical review of mobile applications for depression: exploring the app marketplace. 2019. http://eprints.lancs.ac.uk/132009/1/CMH_2019_ Symposium_Poster_Dionne_Bowie.pdf. Accessed 14 June 2019.

Brodie MA, Pliner EM, Ho A, Li K, Chen Z, Gandevia SC, et al. Big data vs accurate data in health research: large-scale physical activity monitoring, smartphones, wearable devices and risk of unconscious bias. Med Hypotheses. 2018;119:32-6.

Bröhl C, Rasche P, Jablonski J, Kumar S, Wille M, Mertens A. Desktop PC, tablet $\mathrm{PC}$, or smartphone? An analysis of use preferences in daily activities for different technology generations of a worldwide sample. In: Zhou J, Salvendy G, editors. Human aspects of IT for the aged population. acceptance, communication and participation. ITAP 2018. Lecture notes in computer science, vol. 10926. Cham: Springer; 2018.

Brown MT, Bussell JK. Medication adherence: WHO cares? Mayo Clin Proc. 2011;86:304-14.

Byambasuren O, Sanders S, Beller E, Glasziou P. Prescribable mHealth apps identified from an overview of systematic reviews. NPJ Digit Med. 2018;1:12.

Carpenter-Song E, Noel VA, Acquilano SC, Drake RE. Real-world technology use among people with mental illnesses: qualitative study. JMIR Ment Health. 2018;5:e10652.

Carroll JK, Moorhead A, Bond R, LeBlanc WG, Petrella RJ, Fiscella K. Who uses mobile phone health apps and does use matter? A secondary data analytics approach. J Med Internet Res. 2017;19:e125.

Chapman C, Champion KE, Birrell L, Deen H, Brierley ME, Stapinski LA, et al. Smartphone apps about crystal methamphetamine ("ice"): systematic search in app stores and assessment of composition and quality. JMIR Mhealth Uhealth. 2018;6:e10442.

Charette RN. Healthcare IT systems: tempting targets for ransomware. IEEE Spectrum. Feb 1 2018. https://spectrum.ieee.org/riskfactor/computing/ it/healthcare-it-systems-tempting-targets-for-ransomware. Accessed 14 June 2019

Chen J, Cade JE, Allman-Farinelli M. The most popular smartphone apps for weight loss: a quality assessment. JMIR Mhealth Uhealth. 2015;3:e104.

Choi YK, Demiris G, Lin SY, Iribarren SJ, Landis CA, Thompson HJ, et al. Smartphone applications to support sleep self-management: review and evaluation. J Clin Sleep Med. 2018;14:1783-90.

Cohen IG, Mello MM. HIPAA and protecting health information in the 21st century. JAMA. 2018;320:231-2.

Computer Economics. IT Spending as a percentage of revenue by industry, company size, and region. 2019. https://www.computereconomi cs.com/article.cfm?id=2626. Accessed 14 June 2019.

comScore. The 2017 U.S. Cross-Platform Future in Focus. 2017a. https://www. comscore.com/Insights/Presentations-and-Whitepapers/2017/2017US-Cross-Platform-Future-in-Focus. Accessed 14 June 2019.

comScore. The 2017 US mobile app report. 2017b. https://www.comscore. com/Insights/Presentations-and-Whitepapers/2017/The-2017-USMobile-App-Report. Accessed 14 June 2019.

Conell J, Bauer R, Glenn T, Alda M, Ardau R, Baune BT, et al. Online information seeking by patients with bipolar disorder: results from an international multisite survey. Int J Bipolar Disord. 2016;4:17.

Coppetti T, Brauchlin A, Müggler S, Attinger-Toller A, Templin C, Schönrath F, et al. Accuracy of smartphone apps for heart rate measurement. Eur J Prev Cardiol. 2017;24:1287-93.

Cornet VP, Holden RJ. Systematic review of smartphone-based passive sensing for health and wellbeing. J Biomed Inform. 2018;77:120-32.
Correa T, Pavez I, Contreras J. Digital inclusion through mobile phones?: a comparison between mobile-only and computer users in internet access, skills and use. Inf Commun Soc. 2018;19:1-8.

Crane D, Garnett C, Brown J, West R, Michie S. Behavior change techniques in popular alcohol reduction apps: content analysis. J Med Internet Res. 2015;17:e118.

Davis J. FDA regulation of mobile apps. ABA (American Bar Association) Practice points. 2017. https://www.americanbar.org/groups/litigation/ committees/products-liability/practice/2017/fda-regulation-of-mobil e-medical-apps/. Accessed 14 June 2019.

Day S, Zweig M. Beyond wellness for the healthy: digital health consumer adoption 2018. 2019. Rock Health. https://rockhealth.com/reports/ beyond-wellness-for-the-healthy-digital-health-consumer-adoption2018/. Accessed 14 June 2019

del Rosario MB, Redmond SJ, Lovell NH. Tracking the Evolution of smartphone sensing for monitoring human movement. Sensors (Basel). 2015;15:18901-33.

Deloitte. The App economy in the United States. 2018. https://www.ftc. gov/system/files/documents/public_comments/2018/08/ftc-20180048-d-0121-155299.pdf. Accessed 14 June 2019.

Di Matteo D, Fine A, Fotinos K, Rose J, Katzman M. Patient willingness to consent to mobile phone data collection for mental health apps: structured questionnaire. JMIR Ment Health. 2018;5:e56.

Dogan E, Sander C, Wagner X, Hegerl U, Kohls E. Smartphone-based monitoring of objective and subjective data in affective disorders: where are we and where are we going? Systematic review. J Med Internet Res. 2017;19:e262.

DOJ (US Department of Justice). How to protect your networks from ransomware: interagency technical guidance document. 2016. https://www. justice.gov/criminal-ccips/file/872771/download. Accessed 14 June 2019.

Donovan F. Healthcare continues to bear the brunt of ransomware attacks. health it security. Health IT Security. 2018. https://healthitsecurity.com/ news/healthcare-continues-to-bear-the-brunt-of-ransomware-attacks. Accessed 14 June 2019

Dragovic M, Davison S, Morgan VA, Chiu VW, Richards N, Vatskalis T. Validated, easy to use and free': top three requests for mobile device applications ('apps') from mental health consumers and clinicians. Adv Mental Health. 2018. https://doi.org/10.1080/18387357.2018.1557014.

Elhai JD, Dvorak RD, Levine JC, Hall BJ. Problematic smartphone use: a conceptual overview and systematic review of relations with anxiety and depression psychopathology. J Affect Disord. 2017;207:251-9.

Elvy S. Commodifying consumer data in the era of the internet of things. 2018. 59 Boston College Law Review 423 (2018). https://ssrn.com/abstr act $=3058855$. Accessed 14 June 2019 .

Ernsting C, Dombrowski SU, Oedekoven M, Sullivan JL, Kanzler M, Kuhlmey A, et al. Using smartphones and health apps to change and manage health behaviors: a population-based survey. J Med Internet Res. 2017:19:e101.

Etkin J. The hidden cost of personal quantification. J Consum Res. 2016:42:967-84.

Executive Office. Big data: a report on algorithmic systems, opportunity, and civil rights. 2016. https://obamawhitehouse.archives.gov/sites/default/ files/microsites/ostp/2016_0504_data_discrimination.pdf. Accessed 14 June 2019

Fair Warning. Canada Patient privacy survey. 2011 b. https://www.fairwarnin g.com/wp-content/uploads/2015/09/2011-12-WP-CANADA-PATIENTSURVEY1.pdf. Accessed 14 June 2019.

Fair Warning. UK Patient privacy survey. 2011a. https://www.fairwarning.com/ wp-content/uploads/2015/09/2011-10-WP-UK-PATIENT-SURVEY1.pdf. Accessed 14 June 2019.

Faurholt-Jepsen M, Frost M, Vinberg M, Christensen EM, Bardram JE, Kessing LV. Smartphone data as objective measures of bipolar disorder symptoms. Psychiatry Res. 2014;217:124-7.

Faurholt-Jepsen M, Frost M, Ritz C, Christensen EM, Jacoby AS, Mikkelsen $\mathrm{RL}$, et al. Daily electronic self-monitoring in bipolar disorder using smartphones - the MONARCA I trial: a randomized, placebo-controlled, single-blind, parallel group trial. Psychol Med. 2015;45:2691-704.

Faurholt-Jepsen M, Bauer M, Kessing LV. Smartphone-based objective monitoring in bipolar disorder: status and considerations. Int J Bipolar Disord. 2018;6(1):6 
Faurholt-Jepsen M, Frost M, Christensen EM, Bardram JE, Vinberg M, Kessing LV. The effect of smartphone-based monitoring on illness activity in bipolar disorder: the MONARCA II randomized controlled single-blinded trial. Psychol Med. 2019. https://doi.org/10.1017/s0033291719000710.

FDA. FDA approves pill with sensor that digitally tracks if patients have ingested their medication. 2017a. https://www.fda.gov/news-events/ press-announcements/fda-approves-pill-sensor-digitally-tracks-if-patie nts-have-ingested-their-medication. Accessed 12 Sept 2019.

FDA. Is a new 510(k) required for a modification to the device? 2017b. https:// www.fda.gov/medical-devices/premarket-notification-510k/new-510krequired-modification-device. Accessed 14 June 2019.

Feehan LM, Geldman J, Sayre EC, Park C, Ezzat AM, Yoo JY, et al. Accuracy of Fitbit devices: systematic review and narrative syntheses of quantitative data. JMIR Mhealth Uhealth. 2018;6:e10527.

Felde M. Wearable medical devices give abundant data_-and risks. The Doctors Company. 2019. https://www.thedoctors.com/articles/wearablemedical-devices-give-abundant-dataand-risks/. Accessed 14 June 2019.

Fernández C, de Salles AA, Sears ME, Morris RD, Davis DL. Absorption of wireless radiation in the child versus adult brain and eye from cell phone conversation or virtual reality. Environ Res. 2018;167:694-9.

Ferron JC, Brunette MF, Geiger P, Marsch LA, Adachi-Mejia AM, Bartels SJ. Mobile phone apps for smoking cessation: quality and usability among smokers with psychosis. JMIR Hum Factors. 2017;4(1):e7.

Firth J, Torous J. Smartphone apps for schizophrenia: a systematic review. JMIR Mhealth Uhealth. 2015;3:e102.

Fleming T, Bavin L, Lucassen M, Stasiak K, Hopkins S, Merry S. Beyond the trial: systematic review of real-world uptake and engagement with digital self-help interventions for depression, low mood, or anxiety. J Med Internet Res. 2018;20:e199.

Fokkema T, Kooiman TJ, Krijnen WP, Van Der Schans CP, Groot DE. Reliability and validity of ten consumer activity trackers depend on walking speed. Med Sci Sports Exerc. 2017:49:793-800.

Foster KR, Callans DJ. Smartphone apps meet evidence-based medicine: the future of medicine may (or may not) be in your smartphone. IEEE Pulse. 2017:8:34-9.

Frazee J, Finley M, Rohack JJ. mHealth and unregulated data: is this farewell to patient privacy. Ind Health L Rev. 2016;13:384.

FTC (US Federal Trade Commission). Mobile health apps interactive tool. Developing a mobile health app. 2016. https://www.ftc.gov/tips-advic e/business-center/guidance/mobile-health-apps-interactive-tool. Accessed 14 June 2019.

Gage D. The venture capital secret: 3 out of 4 start-ups fail. Wall Street J. 2012;19:20

Gandhi OP. Microwave emissions from cell phones exceed safety limits in europe and the US when touching the body. IEEE Access. 2019:7:47050-2.

Gandhi OP, Morgan LL, de Salles AA, Han YY, Herberman RB, Davis DL. Exposure limits: the underestimation of absorbed cell phone radiation, especially in children. Electromagn Biol Med. 2012;31:34-51.

Gangadharan SP. The downside of digital inclusion: expectations and experiences of privacy and surveillance among marginal Internet users. New Media Soc. 2017;19:597-615.

Gartner. Gartner Says worldwide wearable device sales to grow 26 percent in 2019. 2018. https://www.gartner.com/en/newsroom/press-relea ses/2018-11-29-gartner-says-worldwide-wearable-device-sales-togrow-. Accessed 14 June 2019

Glenn T, Monteith S. New measures of mental state and behavior based on data collected from sensors, smartphones, and the Internet. Curr Psychiatry Rep. 2014a; 16:523.

Glenn T, Monteith S. Privacy in the digital world: medical and health data outside of HIPAA protections. Curr Psychiatry Rep. 2014b;16:494.

Glick G, Druss B, Pina J, Lally C, Conde M. Use of mobile technology in a community mental health setting. J Telemed Telecare. 2016;22:430-5.

Godfrey A, Hetherington V, Shum H, Bonato P, Lovell NH, Stuart S. From A to Z: wearable technology explained. Maturitas. 2018;113:40-7.

Gonzales A. The contemporary US digital divide: from initial access to technology maintenance. Inf Commun Soc. 2016;19:234-48.

Goodday SM, Cipriani A. Challenges in identifying behavioural markers of bipolar disorder through objective smartphone data. Aust N Z J Psychiatry. 2019;53:168-9.
Google. 2016. This year's Founders' Letter. 2016. https://www.blog.google/insid e-google/alphabet/this-years-founders-letter/. Accessed 14 June 2019.

Gostin LO, Halabi SF, Wilson K. Health data and privacy in the digital era. JAMA. 2018;320:233-4.

GPS.gov. GPS Accuracy. 2017. https://www.gps.gov/systems/gps/performanc e/accuracy/. Accessed 14 June 2019.

Grammenos A, Mascolo C, Crowcroft J. You are sensing, but are you biased?: a user unaided sensor calibration approach for mobile sensing. Proc ACM Interact Mob Wearable Ubiquitous Technol. 2018;2:11.

Grewal M, Andrews A. How good is your gyro [ask the experts]. IEEE Control Syst Mag. 2010;30:12-86.

Gringras P, Middleton B, Skene DJ, Revell VL. Bigger, brighter, bluer-better? Current light-emitting devices-adverse sleep properties and preventative strategies. Front Public Health. 2015;3:233.

Grundy Q, Chiu K, Held F, Continella A, Bero L, Holz R. Data sharing practices of medicines related apps and the mobile ecosystem: traffic, content, and network analysis. BMJ. 2019;364:1920

Gruwez A, Bruyneel AV, Bruyneel M. The validity of two commercially-available sleep trackers and actigraphy for assessment of sleep parameters in obstructive sleep apnea patients. PLoS ONE. 2019;14:e0210569.

GSMA (Groupe Spéciale Mobile). The mobile economy 2018. 2018a. https:// www.gsma.com/mobileeconomy/. Accessed 14 June 2019.

GSMA. Consumer Insights. Evaluating mobile engagement. 2018b. https:// www.gsmaintelligence.com/research/2018/02/consumer-insightsevaluating-mobile-engagement/661/. Accessed 14 June 2019.

Harrison PJ, Cipriani A, Harmer CJ, Nobre AC, Saunders K, Goodwin GM, et al. Innovative approaches to bipolar disorder and its treatment. Ann NY Acad Sci. 2016;1366:76-89.

Hendrikoff L, Kambeitz-llankovic L, Pryss R, Senner F, Falkai P, Pogarell O, et al. Prospective acceptance of distinct mobile mental health features in psychiatric patients and mental health professionals. J Psychiatr Res. 2019;109:126-32.

Herbert R, Kim JH, Kim YS, Lee HM, Yeo WH. Soft material-enabled, flexible hybrid electronics for medicine, healthcare, and human-machine interfaces. Materials. 2018;1 1:187.

HHS (US Department of Health \& Human Services). Health care industry cybersecurity task force. Report on improving cybersecurity in the health care industry. 2017. https://www.phe.gov/Preparedness/plann ing/CyberTF/Pages/default.aspx. Accessed 14 June 2019.

Hill S. Can you really trust app store ratings? We asked the experts. Digital Trends. 2018. https://www.digitaltrends.com/android/can-you-reall y-trust-app-store-ratings/. Accessed 14 June 2019.

HIPAA Journal. Security breach highlights need for patient portals to be pen tested. 2017. https://www.hipaajournal.com/security-breach-highlights -need-for-patient-portals-to-be-pen-tested-8803/. Accessed 14 June 2019.

Hitlin P, Rainie L. Facebook algorithms and personal data. Pew Research Center. 2019. https://www.pewinternet.org/2019/01/16/facebook-algorithms -and-personal-data/. Accessed 14 June 2019.

Huckvale K, Torous J, Larsen ME. Assessment of the data sharing and privacy practices of smartphone apps for depression and smoking cessation. JAMA Netw Open. 2019;2:e192542.

Hughes JF. How wearables could put doctors in HIPAA hot water. PhysicianSense. 2019. https://www.mdlinx.com/physiciansense/how-weara bles-could-put-doctors-in-hipaa-hot-water/. Accessed 14 June 2019.

Huguet A, Rao S, McGrath PJ, Wozney L, Wheaton M, Conrod J, Rozario S. A systematic review of cognitive behavioral therapy and behavioral activation apps for depression. PLoS ONE. 2016;11(5):e0154248.

Hwang K. Dangers of defective mobile health apps and devices. Verywell. 2018. https://www.verywellhealth.com/dangers-of-defective-mobil e-health-apps-and-devices-1739151. Accessed 14 June 2019.

IDC. Ongoing demand fuels a strong growth trajectory for wearable devices in q1 2019 with wrist-worn and ear-worn leading the market, according to IDC. 2019. https://www.idc.com/getdoc.jsp?containerld=prUS4 5115019. Accessed 14 June 2019.

Irving D. What the speed of life means for security and society. Rand Review, 2019. https://www.rand.org/blog/rand-review/2019/03/what-thespeed-of-life-means-for-security-and-society.html. Accessed 14 June 2019. 
Kertz SJ, Kelly JM, Stevens KT, Schrock M, Danitz SB. A review of free iPhone applications designed to target anxiety and worry. J Technol Behav Sci. 2017;2:61.

Kim J, Seo M, David P. Alleviating depression only to become problematic mobile phone users: can face-to-face communication be the antidote? Comput Human Behav. 2015;51:440-7.

Klasnja P, Consolvo S, Choudhury T, Beckwith R, Hightower J. Exploring privacy concerns about personal sensing. International conference on pervasive computing. Berlin: Springer; 2009. p. 176-83.

Klee A, Stacy M, Rosenheck R, Harkness L, Tsai J. Interest in technology-based therapies hampered by access: a survey of veterans with serious mental illnesses. Psychiatr Rehabil J. 2016;39:173-9.

Koetsier J. Google vs Amazon at CES: the battle for the future of voice (and computing). Forbes. 2019. https://www.forbes.com/sites/johnkoetsi er/2019/01/11/google-vs-amazon-at-ces-the-battle-for-the-future-ofvoice-and-computing/\#4f85d4143c68. Accessed 14 June 2019.

Kos A, Tomažič S, Umek A. Evaluation of smartphone inertial sensor performance for cross-platform mobile applications. Sensors (Basel). 2016;16:477.

Krebs P, Duncan DT. Health app use among us mobile phone owners: a national survey. JMIR Mhealth Uhealth. 2015;3:e101.

Kretzschmar K, Tyroll H, Pavarini G, Manzini A, Singh I, Neurox young people's advisory group. Can your phone be your therapist? Young people's ethical perspectives on the use of fully automated conversational agents (chatbots) in mental health support. Biomed Inform Insights. 2019;11:1178222619829083.

Kuerbis A, Mulliken A, Muench F, Moore AA, Gardner D. Older adults and mobile technology: factors that enhance and inhibit utilization in the context of behavioral health. Ment Heal Addict Res. 2017:2:1-11.

Lamkin P. Smart wearables market to double by 2022: \$27 billion industry forecast. Forbes. 2018. https://www.forbes.com/sites/paullamkin /2018/10/23/smart-wearables-market-to-double-by-2022-27-billionindustry-forecast/\#1736ede72656. Accessed 14 June 2019.

Larsen ME, Nicholas J, Christensen H. A systematic assessment of smartphone tools for suicide prevention. PLoS ONE. 2016a;11:e0152285.

Larsen ME, Nicholas J, Christensen H. Quantifying app store dynamics: longitudinal tracking of mental health apps. JMIR Mhealth Uhealth. 2016b:4:e96.

Larsen ME, Huckvale K, Nicholas J, Torous J, Birrell L, Li E, Reda B. Using science to sell apps: evaluation of mental health app store quality claims. NPJ Dig Med. 2019;2:18.

Lee TT, Kesselheim ASUS. Food and Drug Administration precertification pilot program for digital health software: weighing the benefits and risks. Ann Intern Med. 2018;168:730-2.

Lee I, Lee Y. Circuit design in mm-scale sensor platform for future loT applications. In: Kyung CM, Yasuura H, Liu Y, Lin YL, editors. Smart Sensors and Systems. Cham: Springer; 2017. p. 57-81.

Li X, Ortiz PJ, Browne J, Franklin D, Oliver JY, Geyer R, et al. Smartphone evolution and reuse: Establishing a more sustainable model. In: 39th International conference on parallel processing workshops. 2010, pp. 476-484.

Liang Z, Martell MA. Validity of consumer activity wristbands and wearable EEG for measuring overall sleep parameters and sleep structure in freeliving conditions. J Healthc Inform Res. 2018:2:152-78.

Lin JC. Clear evidence of cell phone RF radiation cancer risk [health matters]. IEEE Microw Mag. 2018;19:6-24.

Lipschitz J, Miller CJ, Hogan TP, Burdick KE, Lippin-Foster R, Simon SR, et al. Adoption of mobile apps for depression and anxiety: cross-sectional survey study on patient interest and barriers to engagement. JMIR Ment Health. 2019;6:e11334

Lowe SA, Ólaighin G. Monitoring human health behaviour in one's living environment: a technological review. Med Eng Phys. 2014;36:147-68.

Lupton D. The digitally engaged patient: self-monitoring and self-care in the digital health era. Soc Theory Health. 2013;11:256-70.

Luxton DD, McCann RA, Bush NE, Mishkind MC, Reger GM. mHealth for mental health: integrating smartphone technology. Prof Psychol Res Pract. 2011:42:505-12.

Mack CA. Fifty years of Moore's law. IEEE Trans Semicond Manuf. 2011:24:202-7.

Mandrola J, Foy A. Downsides of detecting atrial fibrillation in asymptomatic patients. Am Fam Physician. 2019;99:354-5.
Marakhimov A, Joo J. Consumer adaptation and infusion of wearable devices for healthcare. Comput Human Behav. 2017;76:135-48.

Martinez-Martin N, Kreitmair K. Ethical issues for direct-to-consumer digital psychotherapy apps: addressing accountability, data protection, and consent. JMIR Ment Health. 2018;5:e32.

McCoy TH Jr, Perlis RH. Temporal trends and characteristics of reportable health data breaches, 2010-2017. JAMA. 2018:320:1282-4.

MicroMD. The HIPAA compliance of wearable technology. blogMD. 2019. https ://www.micromd.com/blogmd/hipaa-compliance-of-wearable-techn ology/. Accessed 14 June 2019.

Minen MT, Stieglitz EJ, Sciortino R, Torous J. Privacy issues in smartphone applications: an analysis of headache/migraine applications. Headache. 2018;58:1014-27.

Miner AS, Milstein A, Schueller S, Hegde R, Mangurian C, Linos E. Smartphonebased conversational agents and responses to questions about mental health, interpersonal violence, and physical health. JAMA Intern Med. 2016;176:619-25.

Mohr DC, Zhang M, Schueller SM. Personal sensing: understanding mental health using ubiquitous sensors and machine learning. Annu Rev Clin Psychol. 2017:13:23-47.

Monteith S, Glenn T. Automated decision-making and big data: concerns for people with mental illness. Curr Psychiatry Rep. 2016;18:112.

Monteith S, Glenn T, Geddes J, Whybrow PC, Bauer M. Big data for bipolar disorder. Int J Bipolar Disord. 2016:4:10.

Moore GE. Cramming more components onto integrated circuits, reprinted from electronics. IEEE Solid-State Circ Newsl. 2006;3:33-5.

Morris RD, Morgan LL, Davis D. Children absorb higher doses of radio frequency electromagnetic radiation from mobile phones than adults. IEEE Access. 2015:3:2379-87.

Murakami H, Kawakami R, Nakae S, Nakata Y, Ishikawa-Takata K, Tanaka S, Miyachi M. Accuracy of wearable devices for estimating total energy expenditure: comparison with metabolic chamber and doubly labeled water method. JAMA Intern Med. 2016;176:702-3.

Napoli PM, Obar JA. The emerging mobile internet underclass: a critique of mobile internet access. Inf Soc. 2014;30:323-34.

Narayanan A. When the business model *is* the privacy violation. Freedom to Tinker. Princeton Center for Information Technology Policy. 2018. https://freedom-to-tinker.com/2018/04/12/when-the-business-model -is-the-privacy-violation/. Accessed 14 June 2019.

NASA. This week at NASA. 2012. https://www.nasa.gov/multimedia/podca sting/TWAN_11_23_12.html. Accessed 14 June 2019.

Nicholas J, Larsen ME, Proudfoot J, Christensen H. Mobile apps for bipolar disorder: a systematic review of features and content quality. J Med Internet Res. 2015;17(8):e198.

Oh JH, Yoo H, Park HK, Do YR. Analysis of circadian properties and healthy levels of blue light from smartphones at night. Sci Rep. 2015;5:11325.

O'Loughlin K, Neary M, Adkins EC, Schueller SM. Reviewing the data security and privacy policies of mobile apps for depression. Internet Interv. 2019:15:110-5.

Packer M. What did the Apple heart study really find? MedPage Today. 2019. https://www.medpagetoday.com/blogs/revolutionandrevelat ion/78684. Accessed 14 June 2019.

Parker L, Bero L, Gillies D, Raven M, Mintzes B, Jureidini J, et al. Mental health messages in prominent mental health apps. Ann Fam Med. 2018;16:338-42.

Parker L, Bero L, Gillies D, Raven M, Grundy Q. The, "hot potato" of mental health app regulation: a critical case study of the Australian policy arena. Int J Health Policy Manag. 2019;8:168-76.

Parpinel M, Scherling L, Lazzer S, Della Mea V. Reliability of heart rate mobile apps in young healthy adults: exploratory study and research directions. J Innov Health Inform. 2017;24:921.

Partnership on Al. Report on algorithmic risk assessment tools in the U.S. criminal justice system. 2019. https://www.partnershiponai.org/repor t-on-machine-learning-in-risk-assessment-tools-in-the-u-s-criminal-justi ce-system/. Accessed 14 June 2019.

Patel $\mathrm{V}$, Johnson C. Individuals' use of online medical records and technology for health needs. ONC Data Brief, no. 40. Washington: Office of the National Coordinator for Health Information Technology; 2018.

Patel N. 90\% Of Startups Fail: Here's What You Need To Know About The 10\%. Forbes. 2015. https://www.forbes.com/sites/neilp 
atel/2015/01/16/90-of-startups-will-fail-heres-what-you-need-to-knowabout-the-10/\#533387ff6679. Accessed 14 June 2019.

Patel V, Hughes P, Barker W, Moon L. Trends in individuals' perceptions regarding privacy and security of medical records and exchange of health information: 2012-2014. ONC Data Brief, no. 33. Washington DC: Office of the National Coordinator for Health Information Technology; 2016.

PCAST (President's Council of Advisors on Science and Technology). Big data and privacy: a technological perspective. 2014. https://obamawhite house.archives.gov/sites/default/files/microsites/ostp/PCAST/pcast _big_data_and_privacy___may_2014.pdf. Accessed 14 June 2019.

Perez S. Report: Voice assistants in use to triple to 8 billion by 2023. TechCrunch. 2019. https://techcrunch.com/2019/02/12/report-voice-assis tants-in-use-to-triple-to-8-billion-by-2023/. Accessed 14 June 2019.

Pew Research. Mobile Fact Sheet. 2018. http://www.pewinternet.org/factsheet/mobile/. Accessed 14 June 2019.

Plante TB, Urrea B, MacFarlane ZT, Blumenthal RS, Miller ER 3rd, Appel LJ, et al. Validation of the instant blood pressure smartphone app. JAMA Intern Med. 2016;176:700-2.

Plante TB, O'Kelly AC, Macfarlane ZT, Urrea B, Appel LJ, Miller ER III, et al. Trends in user ratings and reviews of a popular yet inaccurate blood pressuremeasuring smartphone app. J Am Med Inform Assoc. 2018;25:1074-9.

Posadzki P, Mastellos N, Ryan R, Gunn LH, Felix LM, Pappas Y, et al. Automated telephone communication systems for preventive healthcare and management of long-term conditions. Cochrane Database Syst Rev. 2016;12:CD009921.

Powell AC, Singh P, Torous J. The complexity of mental health app privacy policies: a potential barrier to privacy. JMIR Mhealth Uhealth. 2018;6:e158.

Pratap A, Renn BN, Volponi J, Mooney SD, Gazzaley A, Arean PA, et al. Using mobile apps to assess and treat depression in Hispanic and Latino populations: fully remote randomized clinical trial. J Med Internet Res. 2018:20:e10130.

Pratap A, Atkins DC, Renn BN, Tanana MJ, Mooney SD, Anguera JA, et al. The accuracy of passive phone sensors in predicting daily mood. Depress Anxiety. 2019;36:72-81.

Prayag AS, Najjar RP, Gronfier C. Melatonin suppression is exquisitely sensitive to light and primarily driven by melanopsin in humans. J Pineal Res. 2019;66:e12562.

Puentes J, Montagner J, Lecornu L, Lähteenmäki J. Quality analysis of sensors data for personal health records on mobile devices. In: Bali R, Troshani I, Goldberg S, Wickramasinghe N, editors. Pervasive health knowledge management. New York: Springer; 2013. p. 103-33.

Rasche P, Wille M, Bröhl C, Theis S, Schäfer K, Knobe M, et al. Prevalence of health app use among older adults in Germany: national survey. JMIR Mhealth Uhealth. 2018:6:e26.

Research2Guidance. 325,000 mobile health apps available in 2017-Android now the leading mHealth platform. 2018. https://research2guidan ce.com/325000-mobile-health-apps-available-in-2017/. Accessed 14 June 2019.

Research2Guidance. mHealth App Economics. Current status and future trends in mobile health. 2017. https://research2guidance.com. Accessed 14 June 2019

Research2Guidance. mHealth Economics Research Program. 2016. https:// research2guidance.com. Accessed 14 June 2019.

Robbins R, Krebs P, Jagannathan R, Jean-Louis G, Duncan DT. Health app use among us mobile phone users: analysis of trends by chronic disease status. JMIR Mhealth Uhealth. 2017;5:e197.

Roberts JJ. The business of your face. Fortune. 2019. http://fortune.com/longf orm/facial-recognition/. Accessed 14 June 2019.

Robillard JM, Feng TL, Sporn AB, Lai JA, Lo C, Ta M, et al. Availability, readability, and content of privacy policies and terms of agreements of mental health apps. Internet Interv. 2019;6(17):100243.

Rodde T. 25\% of users abandon an app after one use. 2019. Localytics. http:// info.localytics.com/blog/25-of-users-abandon-apps-after-one-use. Accessed 14 June 2019.

Rohani DA, Faurholt-Jepsen M, Kessing LV, Bardram JE. Correlations between objective behavioral features collected from mobile and wearable devices and depressive mood symptoms in patients with affective disorders: systematic review. JMIR Mhealth Uhealth. 2018;6:e165.

Rosenfeld L, Torous J, Vahia IV. Data security and privacy in apps for dementia: an analysis of existing privacy policies. Am J Geriatr Psychiatry. 2017:25:873-7.
Rowland C. Apple now says its smartwatch tech to detect atrial fibrillation is not for those with atrial fibrillation. Washington Post. 12/6/2018. https ://www.washingtonpost.com/business/economy/apple-now-says-itssmartwatchapp-to-detect-atrial-fibrillation-is-not-for-those-with-atria Ifibrillation/2018/12/06/cb5c46bc-f978-11e8-8c9a-860ce2a8148f_story .html. Accessed 14 June 2019.

RSA. RSA Data Privacy and Security Survey 2019: the growing data disconnect between customers and businesses. 2019. https://www.rsa.com/ content/dam/en/misc/rsa-data-privacy-and-security-survey-2019.pdf. Accessed 14 June 2019.

Savov V. Apple and Samsung feel the sting of plateauing smartphones. The Verge. 2019. https://www.theverge.com/2019/1/3/18166399/iphon e-android-apple-samsung-smartphone-sales-peak. Accessed 14 June 2019.

Schueller SM, Neary M, O'Loughlin K, Adkins EC. Discovery of and interest in health apps among those with mental health needs: survey and focus group study. J Med Internet Res. 2018;20:e10141.

Scott N, Cerulus L, Overly S. How Silicon Valley gamed Europe's privacy rules. 5/22/19. Politico. https://www.politico.eu/article/europe-data-prote ction-gdpr-general-data-protection-regulation-facebook-google/. Accessed 14 June 2019.

Seppälä J, De Vita I, Jämsä T, Miettunen J, Isohanni M, Rubinstein K, et al. Mobile phone and wearable sensor-based mhealth approaches for psychiatric disorders and symptoms: systematic review. JMIR Ment Health. 2019;6:e9819.

Shapiro R, Aneja S. Who owns Americans' personal information and what is it worth? EconVue. 2019. https://econvue.com/pulse/who-owns-ameri cans\%E2\%80\%99-personal-information-and-what-it-worth. Accessed 14 June 2019

Sheng S, Holbrook M, Kumaraguru P, Cranor LF, Downs J. Who falls for phish?: a demographic analysis of phishing susceptibility and effectiveness of interventions. In: Proceedings of the SIGCHI conference on human factors in computing systems. ACM; 2010 Apr 10. pp. 373-82.

Singer N, Merrill JB. When a company is put up for sale, in many cases, your personal data is, too. New York Times. 2015. https://www.nytim es.com/2015/06/29/technology/when-a-company-goes-up-for-sale-inmany-cases-so-does-your-personal-data.html. Accessed 14 June 2019.

Singh K, Drouin K, Newmark LP, Lee J, Faxvaag A, Rozenblum R, et al. Many mobile health apps target high-need, high-cost populations, but gaps remain. Health Aff (Millwood). 2016;35:2310-8.

Singh K, Diamantidis CJ, Ramani S, Bhavsar NA, Mara P, Warner J, et al. Patients' and nephrologists' evaluation of patient-facing smartphone apps for CKD. Clin J Am Soc Nephrol. 2019;14:523-9.

Smith A. Public attitudes toward computer algorithms. Pew Research Center. 2018. https://www.pewinternet.org/2018/11/16/public-attitudes-towar d-computer-algorithms/. Accessed 14 June 2019.

Snell E. Patient data breach fear hinders health data sharing. HealthlTSecurity. 2017. https://healthitsecurity.com/news/patient-data-breach-fearhinders-health-data-sharing. Accessed 14 June 2019.

Solomon R, Sandborn PA, Pecht MG. Electronic part life cycle concepts and obsolescence forecasting. IEEE Trans Compon Packag Technol. 2000;23:707-17.

Statistica. Adult wearable users penetration rate in the United States from 2016 to 2022. 2019c. https://www.statista.com/statistics/793800/usadult-wearable-penetration/. Accessed 14 June 2019.

Statistica. Number of apps available in leading app stores as of 3 rd quarter 2018. 2019a. https://www.statista.com/statistics/276623/number-ofapps-available-in-leading-app-stores/. Accessed 14 June 2019.

Statistica. Worldwide mobile app retention rate during the first 90 days of ownership as of March 2016, by mobile platform. 2019b. https://www. statista.com/statistics/243728/worldwide-mobile-app-user-retentionby-mobile-plaform/. Accessed 14 June 2019.

Sucala M, Cuijpers P, Muench F, Cardoș R, Soflau R, Dobrean A, et al. Anxiety: there is an app for that. A systematic review of anxiety apps. Depress Anxiety. 2017;34:518-25.

Swearingen J. We're no longer in smartphone plateau. we're in the smartphone decline. New York Magazine. 2018. https://nymag.com/intelligen cer/2018/12/global-u-s-growth-in-smartphone-growth-starts-to-decli ne.html. Accessed 14 June 2019. 
Terry NP. A healthcare frame for the Boeing crashes. Harvard Bill of Health Blog. 2019. http://blog.petrieflom.law.harvard.edu/2019/04/08/a-healthcare -frame-for-the-boeing-crashes/. Accessed 14 June 2019.

Thornton LK, Kay-Lambkin FJ. Specific features of current and emerging mobile health apps: user views among people with and without mental health problems. Mhealth. 2018;4:56.

Toner J. Exploring the dark-side of fitness trackers: normalization, objectification and the anaesthetisation of human experience. Perform Enhanc Health. 2018:6:75-81.

Toon E, Davey MJ, Hollis SL, Nixon GM, Horne RS, Biggs SN. Comparison of commercial wrist-based and smartphone accelerometers, actigraphy, and psg in a clinical cohort of children and adolescents. J Clin Sleep Med. 2016:12:343-50.

Torous J, Roberts LW. The ethical use of mobile health technology in clinical psychiatry. J Nerv Ment Dis. 2017;205:4-8.

Torous J, Wisniewski H, Liu G, Keshavan M. Mental health mobile phone app usage, concerns, and benefits among psychiatric outpatients: comparative survey study. JMIR Ment Health. 2018;5:e11715.

Tosini G, Ferguson I, Tsubota K. Effects of blue light on the circadian system and eye physiology. Mol Vis. 2016;22:61-72.

Trewin S, Swart C, Pettick D. Physical accessibility of touchscreen smartphones. In: Proceedings of the 15th international ACM SIGACCESS conference on computers and accessibility. ACM; 2013 Oct 21, p. 19.

Valdez AC, Ziefle M. The users' perspective on the privacy-utility tradeoffs in health recommender systems. Int J Hum Comput Stud. 2019;121:108-21.

van Deursen AJ, van Dijk JA. The first-level digital divide shifts from inequalities in physical access to inequalities in material access. New Media Soc. 2019:21(2):354-7.

Vesnic-Alujevic L, Breitegger M, Guimarães Pereira A. Do-It-Yourself' healthcare? quality of health and healthcare through wearable sensors. Sci Eng Ethics. 2018;24:887-904.

Vezočnik M, Juric MB. Average step length estimation models' evaluation using inertial sensors: a review. IEEE Sens J. 2019;19(2):396-403.

Vinocur N. How one country blocks the world on data privacy. Politico. 2019. https://www.politico.com/story/2019/04/24/ireland-data-priva cy-1270123. Accessed 14 June 2019.
Wahle F, Kowatsch T, Fleisch E, Rufer M, Weidt S. Mobile sensing and support for people with depression: a pilot trial in the wild. JMIR Mhealth Uhealth. 2016;4:e111.

Wang K, Varma DS, Prosperi M. A systematic review of the effectiveness of mobile apps for monitoring and management of mental health symptoms or disorders. J Psychiatr Res. 2018;107:73-8.

Watanabe T, Yamaguchi T, Minatani K. Advantages and drawbacks of smartphones and tablets for visually impaired people: analysis of ict user survey results. IEICE Trans Inf Syst. 2015;98:922-9.

Wiggers K, Top 10 products at CES 2019 that work with Alexa or Google Assistant. VentureBeat. 2019. https://venturebeat.com/2019/01/13/ top-5-products-revealed-at-ces-2019-that-work-with-alexa-and-googl e-assistant/. Accessed 14 June 2019.

Wilson H, Stoyanov SR, Gandabhai S, Baldwin A. The quality and accuracy of mobile apps to prevent driving after drinking alcohol. JMIR Mhealth Uhealth. 2016;4(3):e98.

Wisniewski H, Liu G, Henson P, Vaidyam A, Hajratalli NK, Onnela JP, et al. Understanding the quality, effectiveness and attributes of top-rated smartphone health apps. Evid Based Ment Health. 2019;22:4-9.

Wolbring G, Lashewicz B. Home care technology through an ability expectation lens. J Med Internet Res. 2014;16(6):e155.

Yu JS, Kuhn E, Miller KE, Taylor K. Smartphone apps for insomnia: examining existing apps' usability and adherence to evidence-based principles for insomnia management. Transl Behav Med. 2019;9:110-9.

Zhang M, Ying J, Song G, Fung DS, Smith H. Attention and cognitive bias modification apps: review of the literature and of commercially available apps. JMIR Mhealth Uhealth. 2018;6:e10034.

\section{Publisher's Note}

Springer Nature remains neutral with regard to jurisdictional claims in published maps and institutional affiliations.

\section{Submit your manuscript to a SpringerOpen ${ }^{\odot}$ journal and benefit from:}

- Convenient online submission

- Rigorous peer review

- Open access: articles freely available online

- High visibility within the field

- Retaining the copyright to your article

Submit your next manuscript at $\boldsymbol{\nabla}$ springeropen.com 